\title{
The Impact of Mass Shootings on Gun Policy
}

Michael Luca

Deepak Malhotra

Christopher Poliquin

Working Paper 16-126 


\title{
The Impact of Mass Shootings on Gun Policy
}

\author{
Michael Luca
}

Harvard Business School

Deepak Malhotra

Harvard Business School

Christopher Poliquin

UCLA Anderson School of Management

Working Paper 16-126

Copyright (C) 2016, 2019 by Michael Luca, Deepak Malhotra, and Christopher Poliquin

Working papers are in draft form. This working paper is distributed for purposes of comment and discussion only. It may not be reproduced without permission of the copyright holder. Copies of working papers are available from the author.

Funding for this research was provided in part by Harvard Business School. 


\title{
The Impact of Mass Shootings on Gun Policy
}

\author{
Michael Luca \\ Harvard Business School and NBER \\ <mluca@hbs.edu>
}

Deepak Malhotra

Harvard Business School

<dmalhotra@hbs.edu>

\author{
Christopher Poliquin \\ UCLA Anderson School of Management \\ <chris.poliquin@anderson.ucla.edu>
}

August 2019

\begin{abstract}
There have been dozens of high-profile mass shootings in recent decades. This paper presents three main findings about the impact of mass shootings on gun policy. First, mass shootings evoke large policy responses. A single mass shooting leads to a $15 \%$ increase in the number of firearm bills introduced within a state in the year after a mass shooting. This effect increases with the extent of media coverage. Second, mass shootings account for a small portion of all gun deaths, but have an outsized influence relative to other homicides. Third, when looking at bills that were actually enacted into law, the impact of mass shootings depends on the party in power. The annual number of laws that loosen gun restrictions doubles in the year following a mass shooting in states with Republicancontrolled legislatures. We find no significant effect of mass shootings on laws enacted when there is a Democrat-controlled legislature, nor do we find a significant effect of mass shootings on the enactment of laws that tighten gun restrictions.
\end{abstract}

We thank Joseph Hall and Jessica Li for excellent research assistance. 


\section{Introduction}

Recent decades have witnessed a series of high-profile mass shootings throughout the United States. While most homicides receive little attention from the public, mass shooting incidents are extremely salient. Nonetheless, a common and frequently articulated view is that despite extensive discussion about mass shootings, they have little influence on policymaking.

Should we expect policymakers to propose new legislation in the wake of a mass shooting? Given that the vast majority of gun deaths do not result from mass shootings, it would be difficult to reconcile large responses to mass shootings with basic models of optimal policy aimed exclusively at reducing gun violence. However, mass shootings may have another effect—bringing attention to the issue of gun violence. Mass shootings could potentially lead to policy changes by focusing attention on gun violence, even if they do not provide new information regarding effective policy or change politicians' preferences.

Political scientists have noted that issues tend to rise and fall in importance within a policy agenda, creating periods in which specific policies shift very rapidly and other periods in which they do not change at all (Baumgartner and Jones 1993, Kingdon 1984). In the context of gun violence, events like the Columbine High School shooting in Colorado have led to calls for new restrictions on guns as well as vehement responses from groups that oppose such changes and favor the loosening of gun laws (Goss 2006; Spitzer 2012). More generally, mass shootings may create "policy windows" during which legislatures become receptive to change-potentially due to shifts in the attention of the media and constituents. Nonetheless, the extent to which mass shootings affect policy and the nature of the resulting changes are empirical questions. 
In this paper, we explore the impact of mass shootings on gun policy, constructing a dataset of all U.S. gun legislation and mass shootings over a period of twenty-five years (1989-2014)combining data from a variety of media and government sources. We begin by looking at the extent of deaths resulting from mass shootings relative to other gun deaths. Overall, there are more than 30,000 gun related fatalities in the United States per year. Approximately $56 \%$ of these are suicides and $40 \%$ are homicides. The remaining $4 \%$ are accidents or incidents of undetermined intent. Mass shootings accounted for about $0.13 \%$ of all gun deaths and $0.34 \%$ of gun murders between 1989 and 2014.

Because mass shootings are salient and plausibly random occurrences, we are able to implement a difference-in-differences strategy around the timing of mass shootings to estimate their causal impact on gun regulation. Specifically, we compare gun laws before and after mass shootings, in states where mass shootings occur relative to all other states.

We then present three main findings about the impact of mass shootings on policy. First, mass shootings evoke large policy responses. A single mass shooting leads to an approximately $15 \%$ increase in the number of firearm bills introduced within a state in the year after a mass shooting. This effect is largest after shootings with the most fatalities and is greatest in the Republican-controlled legislatures.

Second, although mass shootings account for a small portion of all gun deaths, they have an outsized influence relative to other homicides. Our estimates suggest that the per-death impact of mass shootings on bills introduced is much larger than the impact of gun homicides in non-mass shooting incidents.

Third, when looking at enacted laws, the impact of mass shootings depends on the party in power. A mass shooting roughly doubles the number of laws enacted in a year that loosen gun 
restrictions in states with Republican-controlled legislatures. We find no significant effect of mass shootings on laws enacted when there is a Democrat-controlled legislature. We also find no significant effect of mass shootings on the number of enacted laws that tighten gun restrictions.

These findings contribute to the political economy literatures on public attention, accountability, policymaking, and law. Empirical research on policymaking emphasizes that factors beyond social welfare - such as ideology, opportunism, and fiscal considerationsinfluence policy (Makowsky and Stratmann 2009; Bardhan and Mookherjee 2010). As we show, mass shootings cause intense legislative activity despite accounting for less than $1 \%$ of firearm deaths, suggesting factors beyond optimal deterrence affect debates concerning gun policy.

Additionally, our results contribute to the literature on issue selection and salience, which examines when and why politicians emphasize or downplay elements of their policy platform (Riker 1996; Petrocik 1996; Dragu and Fan 2016). Our finding that Republican-controlled states loosen restrictions on firearms following mass shootings is consistent with the literature's prediction that politicians in the majority tend to focus policymaking on issues they "own"-i.e. those which they have a reputation for successfully handling in the interests of their constituents. Using this definition, and at least during our sample period, Republicans do appear to have “owned" the gun issue (Goss 2006).

Finally, our results relate to the literature on media and public attention (Eisensee and Strömberg 2007; Durante and Zhuravskaya 2018). We find that mass shootings receive considerable media attention and that this attention is correlated with the number of gun bills introduced following mass shootings, suggesting that increased attention is a plausible mechanism for the higher levels of legislative activity we observe following mass shootings. This sheds light 
on the role of attention and salience in policymaking, and on the interaction between issue salience and political preferences in shaping the degree and direction of enacted policies.

\section{Background and Data}

As described above, of the roughly 30,000 annual gun deaths in the United States, fewer than 100 occur in mass shootings. For the purpose of this paper, we define a "mass shooting" as an incident in which 4 or more people, other than the perpetrator(s), are unlawfully killed with a firearm in a single, continuous incident that is not related to gangs, drugs, or other criminal activity. This definition closely matches the one used by Krouse and Richardson (2015) and the FBI's definition of "mass murder" as 4 or more murders "occurring during the same incident, with no distinctive time period between the murders... typically involv[ing] a single location" (Morton and Hilts 2008). We further restrict our analysis to cases where at least three of the fatalities were individuals unrelated to, and not romantically involved with, the shooter(s). We include spree murders - homicides at multiple locations without a significant pause between incidents — if they result in four or more deaths.

We assemble a list of mass shootings since 1989 from a variety of government and media sources because there is no single, comprehensive government database of mass murders. We first extract all gun-related mass murders (four or more dead) that are not felony related from the FBI supplementary homicide reports (SHR). We then verify each incident in the SHR using media accounts; the SHR may contain errors in which separate homicides in a month are reported as a single incident, which is why it is necessary to verify the incidents with media coverage. Participation in the SHR program is voluntary and many law enforcement agencies do not report detailed data to the FBI. We therefore supplement the FBI data with mass shootings gathered from 
media accounts or compiled by other researchers and journalists interested in the topic. Specifically, we combine the SHR data with data on mass shootings collected by the Mass Shootings in America (MSA) project at Stanford University (Stanford Geospatial Center and Stanford Libraries 2015) and a list created by USA Today (2013). For each shooting, we determine the event location as well as the number of victim fatalities and injuries. We also classify shootings based on the relationship (if any) between the alleged shooter(s) and victims. Previous work on mass shootings (Duwe 2007; Krouse and Richardson 2015) distinguishes between public mass shootings that occur in places frequented by the public, felony-related murders, and familicide. We categorize shootings by whether they are public events or primarily related to domestic conflicts, and we focus on incidents in which at least three people not related or romantically involved with the shooter died. This restriction filters out family-killings in residences as well as family-related murders in public places. ${ }^{1}$

Figure 1 shows the number of incidents and fatalities in mass shootings by year. The data show a slight upward trend in the number of incidents and fatalities over time, but both incidents and fatalities vary substantially from year to year. Figure 2 shows a map of the locations of mass shootings in the United States between 1989 and 2014.

\subsection{Gun Legislation}

State governments are the primary regulators of firearms. Federal laws establish a minimum level of gun control, which is augmented to varying degrees by state and local policies. The federal government has put some restrictions on firearm commerce, the possession of guns by potentially dangerous individuals, and ownership of certain types of firearms and ammunition.

\footnotetext{
${ }^{1}$ A 2006 shooting at a church in Louisiana is one example. A man killed his wife and in-laws while abducting
} her and their children from a church. Only the wife's family was present at the church during the shooting. 
States decide a variety of gun policies ranging from who can purchase and possess a gun to what types of guns are allowed in different situations to how guns should be stored and what types of training should be undertaken by gun owners. Local ordinances can also restrict firearm possession and use, but state statutes enacted in the past few decades have limited the importance of local government in this arena by pre-empting local regulations.

We create a comprehensive dataset of gun legislation in all fifty states using the bill tracking reports service from LexisNexis, which includes all bills introduced in state legislatures since at least 1990 with a synopsis and timeline of each bill's progress. This allows us to determine whether bills pass the legislature and become law. We identify firearm bills by searching for the firearm-related terms "firearm", "handgun", "pistol”, "revolver", "rifle", "shotgun", "long-gun", and "assault weapon." We identify 20,409 firearm bills and 3,199 laws between 1990 and 2014. In other words, there were 20,409 proposals made and 3,199 laws passed in the twenty-five-year sample period across all fifty states. This includes laws that loosen or tighten gun restrictions, and many that do neither or both. We exclude resolutions, executive orders, and ballot initiatives from the analysis. ${ }^{2}$ Figure 3 shows the total number of bills introduced and laws enacted by year.

To explore whether gun control is tightened or loosened after mass shootings, we hired eight people to manually code the summary of bills that became law. Coders were given instructions explaining how to code legislation, but were otherwise blind to the topic and design of the study. We presented bill summaries from LexisNexis to coders in randomly chosen groups

${ }^{2}$ Our data source-Lexis Advance-includes resolutions, but it's unclear whether it includes all executive orders or ballot initiatives. Including those we do have along with all resolutions does not meaningfully change the results-the correlation between our measure of legislation and a measure including these other actions is 0.99. In addition, legislators in some states first submit ideas for bills in the form of a "draft request" or similar document. We exclude these from our analyses because they result in double counting some legislation. We instead focus only on actual bills. 
of 50. Two people coded each summary, and no coder saw the same summary multiple times. For each summary, coders decided whether the bill was tightening (stricter gun control), loosening (weaker gun control), uncertain (insufficient information), both tightening and loosening, or neither tightening nor loosening (neutral). There were therefore five possible labels for bills: tighten, loosen, both, neutral, or uncertain. Appendix A shows example bill summaries and their expected labels.

To cross-validate (and incentivize) the bill coding, we coded a small fraction of bills ourselves as a baseline comparison point. For this process, we blinded ourselves from any information about when or where the bill was proposed. We then used our scores to assess the quality of coders. Specifically, each group of 50 bills given to a coder contained five bills that we had also coded (they did not know which bills were and weren't coded by us, and did not have access to any of our assessments of whether a bill was looser or tighter). Coders were paid up to a $50 \%$ bonus based on the extent to which their coding matched ours (which we simply told them was a "gold standard" of known codes).

Across all five categories, the two coders for each bill agreed with each other $52 \%$ of the time (the agreement rate would be $20 \%$ by chance) and agreed with the gold standard $71 \%$ of the time. Coders performed worst on the neutral category, and best on the tighten-only and loosenonly categories; when a bill tightens gun control (according to the gold standard), the two coders agree on tightening $67 \%$ of the time, and when a bill loosens gun control, they agree on loosening $60 \%$ of the time. The fact coders were not able to agree on a category for $48 \%$ of laws reduces the sample available for analysis and is a limitation of our study. In principle, laws might be unclear for coders either because the law is relatively minor and intended to be window dressing, or because it was complicated for the coders to read (leading to coder errors or ambiguity). To 
explore, we compared 100 random laws that coders disagreed about to 100 they agreed on. We then classified each as a minor (e.g. convening a committee to study an issue) or major (e.g. allowing guns in schools) policy change. We find a similar number of minor laws in both samples, suggesting that coder disagreement likely results from coder inattention rather than laws being especially likely to be minor policy changes. We do not see differences in the rate of disagreement among coders about laws enacted in the wake of a mass shooting, relative to laws enacted at other times. Appendix A includes a breakdown of the coding for all 3,199 laws, further discussion of coder agreement, and examples of bills that coders found difficult.

Most importantly for the purposes of our analysis, however, is that when the two coders of a bill agree with each other on tightening, they also agree with our coding $93 \%$ of the time; when the two coders agree on loosening, they are consistent with our scores $91 \%$ of the time. When analyzing the direction of policy change, we leverage this high degree of reliability by restricting our analysis to laws that coders agreed were designed to tighten or loosen gun control. ${ }^{3}$ Because states can pass either, none, or both types of laws in a year, our dependent variable is the count of laws in each direction.

Figure 4 shows mean bills introduced, laws enacted, and tightening and loosening laws by political control of the state legislature. Republicans enact more laws loosening gun control, and fewer laws tightening gun control, than do Democrats. Republican, Democratic, and split legislatures enact a similar number of total gun laws. The coders who classified the legislation were only given summaries of each bill; they were not provided with the state, year, or any information on political affiliation.

${ }^{3}$ This is $37 \%$ of all enacted laws in our data. As mentioned, nearly half of laws cannot be categorized because coders disagreed on the classification. Another $13 \%$ are not used because coders agreed they were neutral or uncertain. 


\subsection{Control Variables}

Our main specification controls for state and year fixed effects, as well as an indicator for whether the legislature is in a regular session in the given year, and whether it is the first year of a legislative biennium (since bills are more likely to be enacted then). Specifically, we create two dummy variables. First, we create a dummy for legislatures that held a regular session in a given year because not all legislatures meet annually. Legislatures that are not in regular session would have to rely on special sessions, which can be difficult to call, in order to consider new gun legislation (though some do this). Second, we control for the first year of each legislative biennium (a two-year period of law making), which varies by whether states hold elections in odd or even years. Typically, more bills are introduced during the first year of the biennium, which leads to alternating years of high and low bill introductions (Figure 3). Building on this main specification, we then add time varying controls as a robustness check. These include economic and demographic factors such as unemployment, divorce rates, and rates of military service. We then layer on controls for the political party in power, since the direction of proposed changes often vary between Democrats (who generally favor more restrictive gun laws) and Republicans (who generally favor less restrictive gun laws). Table 1 contains summary statistics for all variables used in the analyses.

\section{The Impact of Mass Shootings on Gun Policy}

\subsection{Identification Strategy}

We implement a difference-in-differences strategy that compares gun laws before and after mass shootings, in states where mass shootings occur relative to all other states. Our dependent variables are counts of bills or enacted laws at the state-year level. We study the effect of mass shootings using Poisson regressions with conditional mean: 


$$
\mathbf{E}\left[y_{s, t} \mid \alpha_{s}, \lambda_{t}, \operatorname{Shoot}_{s, t-1}, X_{s, t}\right]=\exp \left(\alpha_{s}+\lambda_{t}+\delta_{s} t+\beta \operatorname{Shoot}_{s, t-1}+\gamma^{\prime} X_{s, t}\right)
$$

where $y_{s, t}$ is a count of bills introduced or laws enacted in state $s$ and year $t ; \alpha_{s}$ and $\lambda_{t}$ are state and year fixed effects; the $\delta_{s} t$ are state-specific time trends; Shoot $t_{s, t-1}$ is either an indicator for states with a mass shooting or the fatality count in mass shootings, and $X_{s, t}$ is a vector of timevarying political, economic, and demographic factors. We estimate the parameters via maximum likelihood by conditioning on the sum of $y_{s, t}$ within states and including year indicators. ${ }^{4}$

Our identification allows us to measure the impact of a mass shooting within that state, controlling for other changes that are happening at the national level. Because this identification strategy does not identify national responses to mass shootings (which would be absorbed by our year effect), our estimates of changes in gun policy may underestimate the total impact of a mass shooting. We can and do account for potential spillovers into neighboring states, but do not see significant spillover effects; these results are presented in Appendix B.

\subsection{The Effect of Mass Shootings on Gun Bill Introductions}

Table 2 shows that a mass shooting leads to a $15 \%$ increase in firearm bills introduced (column 4). For the average state, this amounts to an additional 2.4 firearm bills introduced in the year following a mass shooting. Mass shootings with more deaths lead to larger effects. On average, each additional death in a mass shooting leads to a $2.3 \%$ increase in the number of gun bills introduced (column 8). These results hold for both Republican-controlled and Democratcontrolled legislatures, for alternative victim thresholds used to define mass shootings, models that

\footnotetext{
${ }^{4}$ It is possible that the number of bills introduced in a given year within a state would depend on the number introduced in recent years in ways that we do not capture with the state fixed effects or time trends. To allow for this possibility, we also estimated an exponential feedback model in which past legislative activity can affect current activity. Our results suggest past legislation does not substantively affect current legislation; state fixed effects adequately capture time series persistence in legislation and the coefficient estimate for the impact of mass shootings is similar in the exponential feedback model.
} 
examine the year of the shooting in addition to the previous year, and models that use the log of fatalities instead of the count. ${ }^{5}$

\subsection{Comparing Mass Shootings and Non-Mass Shootings}

Table 3 shows that fatalities resulting from mass shootings lead to much larger increases in gun bill introductions than gun homicides in non-mass shooting incidents. We estimate the models in this table using mass shooting fatalities and ordinary gun homicides per 100,000 people to facilitate comparison between the two types of murder. Our estimates are imprecise, but suggest it would take approximately 125 people dying in individual gun homicide incidents to have as much impact on bills introduced as each person who dies in a mass shooting. There are, however, a number of caveats to this estimate. First, ordinary gun homicides are less random than mass shootings and therefore not exogenous in the model. Second, the victims of mass shootings and ordinary gun homicides have different attributes; the impact of mass shootings is not easily decomposed into the effect of victim count, media salience, and attributes of the victims. Any differences in response between ordinary and mass shootings could be driven in part by attributes of the victims. Our estimates, however, are still suggestive evidence that mass shootings tend to have a greater impact on legislative activity than changes in the ordinary gun homicide rate.

\subsection{The Role of Political Party on Laws Enacted}

As mentioned previously, the two major political parties in the United States differ dramatically in their stances on how restrictive gun policy should be, with the Republican Party favoring fewer gun restrictions. ${ }^{6}$ To look at the impact of political parties on gun policy, we restrict

\footnotetext{
${ }^{5}$ Results by political affiliation are presented in Table 4 and discussed in section 3.4 below. Results using alternative victim thresholds for the definition of mass shooting (e.g. 5+, 7+, 10+ deaths) and alternative models are available from the authors upon request.

${ }^{6}$ See, for example, https://www.gop.com/platform/and https://www.democrats.org/party-platform.
} 
our analysis to enacted laws, all of which were coded for whether they loosened or tightened gun restrictions (see data description for more details).

Tables 4 and 5 show the effect of mass shootings interacted with Democrat and Republican control of state legislatures. The results show that Democrats and Republicans respond differently to mass shootings. Table 4 shows that Republicans introduce $48 \%$ more bills and Democrats introduce $11 \%$ more bills following mass shootings than in other years, although the coefficient for Democrats is not statistically significant. ${ }^{7}$ The results also indicate that Republican legislatures enact $32 \%$ more laws the year after a mass shooting than in other years, a statistically significant increase. Democratic legislatures enact 7\% more laws the year after a mass shooting, but this estimate is imprecise and not statistically significant. ${ }^{8}$

When there is a Republican-controlled legislature, mass shootings lead to more firearm laws that loosen gun control (Table 5). Our point estimates indicate that a mass shooting in the previous year increases the number of enacted laws that loosen gun restrictions by $115 \%$ in states with Republican-controlled legislatures. When there is a Democrat-controlled legislature, mass shootings lead to a statistically insignificant reduction in laws that loosen gun control. This result is similar across models using the count of fatalities instead of a shooting indicator, across alternative victim thresholds, with or without year fixed effects, with or without control variables, and when we include only a limited set of controls. ${ }^{9}$ We find no significant effects of mass shootings on laws that tighten gun restrictions, but the estimates are imprecise.

7 The difference between Republicans and Democrats is statistically significant at the 0.05 level.

8 The difference between Republicans and Democrats in terms of enacted laws is not statistically significant. Without interacting mass shooting with political party, there is a $9 \%$ increase in gun laws enacted (i.e. bills that become law) after a mass shooting relative to other years, but this estimate is imprecise (Appendix C).

${ }^{9}$ Available from authors upon request. The coefficients tend to be larger in magnitude for shootings resulting in more deaths (e.g. a dummy for shootings that causes 6-9 deaths has a larger coefficient than a dummy for shootings causing 4-5 deaths). The effect for tightening laws is statistically significant and positive-for both 
The finding that Republicans - who typically favor fewer restrictions on gun owners—are more active in introducing and passing new legislation following mass shootings is consistent with hypotheses in the literature on how issue salience affects policy decisions (Riker 1996; Petrocik 1996; Dragu and Fan 2016). These models of issue selection suggest that Republican-controlled legislatures might respond to increased attention to gun policy by introducing new legislation because Republican voters: (a) tend to be in favor of expanding gun rights and access to guns (Parker et al. 2017), (b) often argue that such actions reduce gun crime (Parker et al. 2017), and (c) are more likely than Democratic voters (during our sample period) to mobilize for political action on this issue (Goss 2006). ${ }^{10}$ Research suggests that supporters of gun rights are more likely to advocate for their positions by writing letters or donating money (Schuman and Presser 1981) and are better-organized than citizens favoring gun control; membership in pro-gun-control organizations, for example, is less than $10 \%$ of the National Rifle Association's membership (Goss 2006). ${ }^{11}$

Anecdotally, there are several examples of Republican lawmakers proposing looser gun laws in response to mass shootings. In the year after the mass shooting at Marjory Stoneman Douglas High School, Florida passed legislation allowing teachers and volunteers to carry guns in schools. Republican Rep. Chuck Brannan explained the rationale: "It allows the good guys to stop the bad. The bad guys will never know when the good guys are there to shoot back."12 Similarly, Texas expanded its school marshal program, which trains teachers to carry weapons, the year after

Democrats and Republicans-only for shootings causing 10+ deaths. This result, however, is identified from only 11 state-year observations due to the rarity of mass shootings that kill 10 or more people.

${ }^{10}$ Republicans appear more likely than Democrats to enact new gun legislation in the absence of a mass shooting (see Table 4, $p=0.08$ ).

${ }^{11}$ Goss (2006) further analyzes the reasons why gun rights organizations have been better organized and more successful than gun control advocates.

${ }^{12}$ Anderson, Curt. "Florida lawmakers pass bill allowing more armed teachers." AP News. 1 May 2019. 
a shooting at Santa Fe High School. Republican Rep. Tony Tinderholt suggested that "what stops people with guns is other people with guns." $" 13$

Overall, the observed effects of mass shootings in Republican-controlled states on bill introductions, laws enacted, and loosening laws suggest that there are relevant changes to gun policy following mass shootings. However, it is possible that mass shootings also lead to an uptick in minor proposals as well; legislators may want to signal that they are making changes even if the new laws have only unsubstantial effects on policy in practice. To further examine this possibility, we look at the impact of mass shootings on laws our coders agreed where neutral since these tend to be more minor proposals (e.g. changing the official responsible for storing certain records). As seen in Appendix D, we do not see statistically significant changes in the number of neutral law changes, although the point estimate is positive.

\subsection{Media Coverage and Mass Shootings}

To explore the potential role of media in increasing the salience of mass shootings, we assemble a dataset of television news coverage related to guns. We measure the seconds of gunrelated news coverage on the national, evening news programs of the three major television networks - NBC, $\mathrm{ABC}$ and $\mathrm{CBS}$ - using data from the Vanderbilt Television News Archive (VTNA). ${ }^{14}$ This source has been used in prior research to measure media attention to natural disasters (Eisensee and Strömberg 2007) and the Israeli-Palestinian conflict (Durante and Zhuravskaya 2018). We exclude cable news networks because data on their news coverage is not available for our sample period. To calculate total gun-related news coverage, we take all news segments that mention gun-related words in either the segment title or summary provided by

\footnotetext{
13 Vertuno, Jim. “Texas seeks more armed school personnel after mass shooting.” AP News. 7 May 2019.
}

14 The Vanderbilt Television News Archive is accessible online at https://tvnews.vanderbilt.edu. 
VTNA and exclude segments that include the names of foreign countries. ${ }^{15} \mathrm{We}$ then sum the duration of these news stories by day to create a measure of total gun-related news coverage.

To capture variation in news coverage across shootings, we aggregate news coverage in the ten days following each mass shooting (including the day of the shooting). The five most covered mass shootings between 1989 and 2014 are the shootings at Sandy Hook Elementary School, a Gabrielle Giffords constituent meeting, Virginia Tech, an Aurora movie theater, and Columbine High School.

Mass shootings increase gun-related media coverage, and shootings that kill more people result in more coverage. Figure 5 shows total seconds of evening news coverage devoted to gunrelated stories around the time of mass shootings. Mass shootings resulting in 10 or more fatalities receive substantially more coverage than shootings resulting 6-9 fatalities, which in turn receive more coverage than shootings with 4-5 fatalities. Appendix E provides further support for this relationship in the form of regression results.

To examine whether the amount of gun-related news coverage following a mass shooting affects policy, we add the measure of media coverage to our model by totaling the amount of gunrelated news coverage following each shooting within a state during the previous year. The results in Table 6 show that the coefficient on news coverage is positive and statistically significant, indicating that more media attention is associated with a greater policy response. One hour of gunrelated news coverage following a mass shooting is associated with a 13 percent increase in the number of gun-related bills introduced in state legislatures (column 4). This suggests that increased salience of gun policy after mass shootings is a plausible mechanism for the relationship between shootings and gun legislation. Media coverage, however, is strongly related to the number of

\footnotetext{
15 This filter removes news stories about foreign wars.
} 
fatalities (see Figure 5), making it difficult to distinguish the impact of media coverage from other attributes of the shooting event.

Unlike other studies of the media's effect on public policy (Eisensee and Strömberg 2007; Durante and Zhuravskaya 2018), our ability to detect policy responses to gun-related news coverage is limited by the small number of events and by the delay between when a mass shooting occurs and when legislatures can act, which is usually not until the next legislative session. The natural disasters studied by Eisensee and Strömberg (2007) and military attacks studied by Durante and Zhuravskaya (2018) number in the thousands, whereas we observe 169 mass shootings. Furthermore, these authors focus on executive actions-whether to provide disaster relief (Eisensee and Strömberg 2007) or launch a military attack (Durante and Zhuravskaya 2018) - that can be taken within hours or days of an event and accompanying news story. Legislative action on the other hand must wait until a legislature is in session and rules allow for the introduction of new bills. Our results overall, however, show that attention shifts to gun violence following mass shootings, and shootings that kill more people receive more media attention. These shifts in attention are a plausible mechanism behind increased legislative activity related to guns in the year following mass shootings

\subsection{Robustness Checks}

In this section, we present four sets of robustness checks. First, we collapse our data into two-year intervals (e.g. by legislative biennium) to ensure the saw-edge pattern in bill introductions (see Figure 3) does not drive our results. Second, we provide support for the exogeneity of mass shootings. Third, we perform a falsification exercise in which we use randomly generated placebo shootings instead of actual shootings; we show there are no effects using the placebo shootings, providing support for our identification strategy. Fourth, we individually drop each state from the 
sample and re-estimate the models to ensure our effect is not driven by a single state or shooting event.

\subsubsection{Analysis by Legislative Biennium}

Figure 3 shows that bill introductions vary substantially between odd- and even-numbered years. We believe this pattern is driven by most states starting their two-year legislative biennium in odd-numbered years, following elections in November of even-numbered years. Many states allow legislators to "carryover" bills that do not pass in the first year of the biennium for consideration in the second year. This means the agenda in the second year of each biennium includes both newly introduced bills and bills introduced the previous year that have been carried over. ${ }^{16}$ Our models control for this pattern by including both year fixed effects and an indicator for the first year of each biennium. To ensure this pattern does not drive our results, however, we estimate models that collapse the data to two-year intervals and regress the total number of bills introduced on the mean of mass shootings (e.g. a variable equal to one if both years of the biennium follow a mass shooting and equal to 0.5 if only one year of the biennium follows a mass shooting). The results are shown in columns 3 and 7 in Table 2, and column 3 in Tables 3 and 6 . The coefficient estimates are less precise, but remain statistically significant and suggest similar effect sizes. The estimate in column 3 of Table 2, for example, suggests mass shootings lead to the introduction of 3.5 more bills for an average state.

\subsubsection{Determinants of Mass Shootings}

Our ability to identify the causal impact of mass shootings on policy rests on the assumption that they are plausibly exogenous to other factors that would drive gun control in a

\footnotetext{
16 Our analyses count each bill once, including it only in the year it was introduced. We count enacted laws in the year of enactment.
} 
given year. Given the erratic nature of mass shootings, this is a plausible assumption. Nonetheless, one might be concerned that both mass shootings and gun policy are being driven by a third variable. To provide support for our assumption and interpretation, we regress an indicator for whether a mass shooting occurs on economic, demographic, and policy variables.

Consistent with the assumption that mass shootings are exogenous with respect to potential confounds, the results in Appendix F show that, out of 32 variables we consider, only unemployment is significantly associated with a higher probability of mass shootings. Because higher unemployment is also associated with a reduction in gun bill introductions (Table 2), the potential bias of this would work in the opposite direction of our finding - making it unlikely that this is driving our results. To further support our interpretation, we control for unemployment in all models. Importantly, bills introduced, laws enacted, and major gun policies do not predict future mass shootings (Appendix F).

\subsubsection{Placebo Tests}

We perform a falsification exercise based on the insights of Bertrand, Duflo, and Mullainathan (2004) and Donald and Lang (2007). Specifically, we randomly assign placebo mass shootings to state-years in which no actual shooting occurred with probability equal to each state's frequency of shootings, and randomly draw a fatality count from the empirical distribution of fatalities. Appendix G shows percentiles of the test statistic based on 1,000 repetitions of this procedure and our actual test statistics from Tables 2 and 5. The results suggest our tests do not over-reject the null hypothesis that mass shootings have no effect on gun policy.

\subsubsection{Excluding Individual States}

To ensure our results are not driven by a single state or shooting, we separately remove each state from the sample and re-estimate the models. Appendix $\mathrm{H}$ presents graphs of the resulting 
50 coefficients for the effect of mass shootings on bills and laws, and coefficients for the Republican and Democrat interaction terms in our analysis of laws that tightened or loosened gun policy. The results show that dropping individual states has little effect on our estimates.

\section{Discussion}

Mass shootings account for a small fraction of gun deaths in the United States, but have a significant impact on gun policy. More gun laws are proposed in the year following a mass shooting. Furthermore, mass shootings seem to have much larger effects on policy, per fatality, than do ordinary gun homicides. These results are broadly consistent with qualitative research that

has hypothesized the possibility of mass shootings precipitating change. For example, Godwin and Schroedel (1998) argue that the Stockton schoolyard massacre in 1989 led to the enactment of California's assault weapons ban. We find large sample empirical evidence that sporadic events such as mass shootings can lead to major policy changes.

We also find that media coverage related to guns increases following mass shootings and that Democrat-controlled and Republican-controlled legislatures differ significantly when it comes to enacting gun laws. Republicans are more likely to loosen gun laws in the year after a mass shooting than in other years. The effect for Democrats, which tends toward a reduction in the loosening of gun restrictions after a mass shooting, is statistically insignificant. This result aligns with the prediction from the political economy literature on issue selection, that political parties emphasize issues that they have a reputation for successfully handling in the eyes of their constituents (Riker 1996; Petrocik 1996; Dragu and Fan 2016).

Our findings raise a number of additional questions, and suggest several directions for future research. First, future research might directly explore the preferences of politicians. 
Republican legislatures could loosen gun restrictions because Republican politicians themselves prefer looser restrictions (as would be the case in a citizen-candidate model) or due to pressure from constituents or interest groups. Consistent with this latter possibility, and our findings, survey evidence suggests that those opposed to increased gun control are more likely than those in favor of additional restrictions to take actions like writing a letter or donating money to support their side (Schuman and Presser 1981). If constituent preferences are driving results, we might expect increased loosening of gun policies in areas with higher rates of gun ownership. To provide exploratory evidence, Appendix I shows the results from adding a proxy for gun ownership to the models. Following Cook and Ludwig (2006), we calculate the percentage of suicides that are firearm related as a proxy for gun ownership and interact this variable with the mass shooting indicator. The coefficient on this variable is not significant either in isolation or when added to the specification with all political interactions. This suggests that changes in support for guns (as proxied by gun ownership) is not the main driver of the policy changes.

Second, our estimates focus on the impact on policy within the state in which each shooting took place. Some mass shootings get national media attention and potentially affect policy nationwide, a result that would not be identified by our fixed effects model. One direction for future research is to develop strategies to identify national responses. With respect to our findings, this suggests that the total impact of mass shootings on gun policy may be even larger than our estimates.

Third, there is a large literature on the impact of gun policies on crime (Duggan 2001; Ludwig and Cook 2000; Ludwig and Cook 2003; Abrams 2012; Luca, Malhotra, and Poliquin 2017). While some gun policies have been extensively researched, many have been difficult to study, which complicates analysis of which policies would be most effective. The relationship we 
find between mass shootings and gun policy raises the possibility of using mass shootings as an instrumental variable to further study the impact of gun laws on gun deaths. Unfortunately, in our sample, mass shootings are not a sufficiently strong instrument to estimate the effects of gun policy on gun deaths, due to their relative infrequency. (Appendix J presents results of this analysis.) This leaves open the possibility of using salient and plausibly random events to instrument for policy changes in future research.

Overall, our results show that even random and infrequent events that account for a relatively small portion of total societal harm (as measured by fatalities in the current study) might nonetheless be crucial levers for policy consideration and change. This does not imply that politicians and policy makers are over-reacting; it may be that on issues where there is usually political deadlock, salient events create opportunities for change that has been sought all along. Whether these changes reflect appropriate responses to the problem remains an open question. 


\section{References}

Abrams, David S. 2012. "Estimating the Deterrent Effect of Incarceration Using Sentencing Enhancements." American Economic Journal: Applied Economics 4 (4): 32-56.

Andrews, Donald W. K., Marcelo J. Moreira, and James H. Stock. 2006. “Optimal Two-Sided Invariant Similar Tests for Instrumental Variables Regression." Econometrica 74 (3): 715-52.

Bardhan, Pranab, and Dilip Mookherjee. 2010. "Determinants of Redistributive Politics: An Empirical Analysis of Land Reforms in West Bengal, India." American Economic Review 100 (4): 1572-1600.

Baum, Christopher F., Mark E. Schaffer, and Steven Stillman. 2007. "Enhanced Routines for Instrumental Variables/generalized Method of Moments Estimation and Testing." The Stata Journal 7 (4): 465-506.

Bertrand, Marianne, Esther Duflo, and Sendhil Mullainathan. 2004. "How Much Should We Trust Differences-in-Differences Estimates?" The Quarterly Journal of Economics 119 (1): 249-75.

Baumgartner, Frank R. and Bryan D. Jones. 1993. Agendas and Instability in American Politics. Chicago, IL: University of Chicago Press.

Bouton, Laurent, Paolo Conconi, Francisco Pino, and Maurizio Zanardi. 2015. "Guns and Votes," working paper.

Cook, Phillip J., and Jens Ludwig. 2006. "The Social Costs of Gun Ownership." Journal of Public Economics 90 (1-2): 379-391.

Donald, Stephen G, and Kevin Lang. 2007. "Inference with Difference-in-Differences and Other Panel Data." Review of Economics and Statistics 89 (2): 221-33.

Dragu, Tiberiu and Xiaochen Fan. 2016. "An Agenda-Setting Theory of Electoral Competition." The Journal of Politics 78 (40): 1170-1182.

Duggan, Mark. 2001. “More Guns, More Crime.” Journal of Political Economy 109 (5): 1086-1114.

Durante, Ruben and Ekaterina Zhuravskaya. 2018. "Attack When the World is Not Watching? US News and the Israeli-Palestinian Conflict." Journal of Political Economy 126 (3): 1085-1133.

Duwe, Grant, 2007. Mass Murder in the United States. North Carolina: McFarland \& Company, Inc.

Egan, Patrick J. and Megan Mullin. 2012. "Turning Personal Experience into Political Attitudes: The Effect of Local Weather on Americans' Perceptions about Global Warming." The Journal of Politics 74 (3): 796-809.

Eisensee, Thomas and David Strömberg. 2007. "News Droughts, News Floods, and U.S. Disaster Relief." The Quarterly Journal of Economics, 122 (2): 693-728. 
Finlay, Keith, and Leandro M. Magnusson. 2009. "Implementing Weak-Instrument Robust Tests for a General Class of Instrumental-Variables Models." The Stata Journal 9 (3): 398-421.

Fuller, Wayne A. (1977). "Some Properties of a Modification of the Limited Information Estimator." Econometrica 45 (4): 939-53.

Godwin, Marcia L., and Jean Reith Schroedel. 1998. "Gun Control Politics in California." In The Changing Politics of Gun Control, edited by John M. Bruce and Clyde Wilcox, 88-110. Lanham, MD: Rowman \& Littlefield Publishers, Inc.

Goss, Kristin A. 2006. Disarmed: The Missing Movement for Gun Control in America. Princeton, NJ: Princeton University Press.

Kingdon, John W. 1984. Agendas, Alternatives, and Public Policies. Boston, MA: Little, Brown \& Company.

Krouse, William and Daniel J. Richardson. 2015. Mass Murder with Firearms: Incidents and Victims, 1999-2013 (CRS Report No. 7-5700). Washington, DC: Congressional Research Service, 2015. https://fas.org/sgp/crs/misc/R44126.pdf.

Levitt, Steven D. 1996. "The Effect of Prison Population Size on Crime Rates: Evidence from Prison Overcrowding Litigation." The Quarterly Journal of Economics 111 (2): 319-51.

Luca, Michael, Deepak Malhotra, and Christopher Poliquin. 2017. "Handgun Waiting Periods Reduce Gun Deaths." Proceedings of the National Academy of Sciences 114 (46): 1216212165.

Ludwig, Jens, and Philip J. Cook. 2000. "Homicide and Suicide Rates Associated with Implementation of the Brady Handgun Violence Prevention Act." JAMA 284 (5): 585-91.

Ludwig, Jens, and Philip J Cook. 2003. Evaluating Gun Policy Effects on Crime and Violence. Washington, D.C.: Brookings Institution Press.

Makowsky, Michael D., and Thomas Stratmann. 2009. "Political Economy at Any Speed: What Determines Traffic Citations?" The American Economic Review 99 (1): 509-27.

Moreira, Marcelo J. 2003. "A Conditional Likelihood Ratio Test for Structural Models." Econometrica 71 (4): 1027-48.

Morton, Robert J. and Mark A. Hilts, eds. 2008. "Serial Murder: Multi-disciplinary perspectives for investigators." Serial Murder Symposium, San Antonio, TX, August 29-September 2, 2005. Washington, DC: Federal Bureau of Investigation, http://www.fbi.gov/statsservices/publications/serial-murder/serial-murder-july-2008-pdf.

Parker, Kim, Juliana Menasce Horowitz, Ruth Igielnik, J. Baxter Oliphant, and Anna Brown. 2017. "America's Complex Relationship with Guns." Pew Research Center. 22 June 2017. https://www.pewsocialtrends.org/2017/06/22/americas-complex-relationship-with-guns/. 
Petrocik, John R. 1996. "Issue Ownership in Presidential Elections, with a 1980 Case Study." American Journal of Political Science 40 (3): 825-850.

Riker, William H. 1996. The Strategy of Rhetoric. New Haven, CT: Yale University Press.

Schuman, Howard and Stanley Presser. 1981. "The Attitude-Action Connection and the Issue of Gun Control." The ANNALS of the American Academy of Political and Social Science 455 (1): 40-47.

Spitzer, Robert J. 2012. The Politics of Gun Control. $5^{\text {th }}$ Ed. Boulder, CO: Paradigm Publishers.

Stanford Geospatial Center and Stanford Libraries. 2015. "Stanford Mass Shootings in America," July 31 release, https://library.stanford.edu/projects/mass-shootings-america.

Stock, James H., and Motohiro Yogo. 2005. "Identification and Inference for Econometric Models." In Identification and Inference for Econometric Models, edited by Donald W. K. Andrews and James H. Stock, 80-108. New York: Cambridge University Press.

USA Today. 2013. "Behind the Bloodshed: The Untold Story of America's Mass Killings," http://www.gannett-cdn.com/GDContent/mass-killings/index.html. 


\section{Figures}
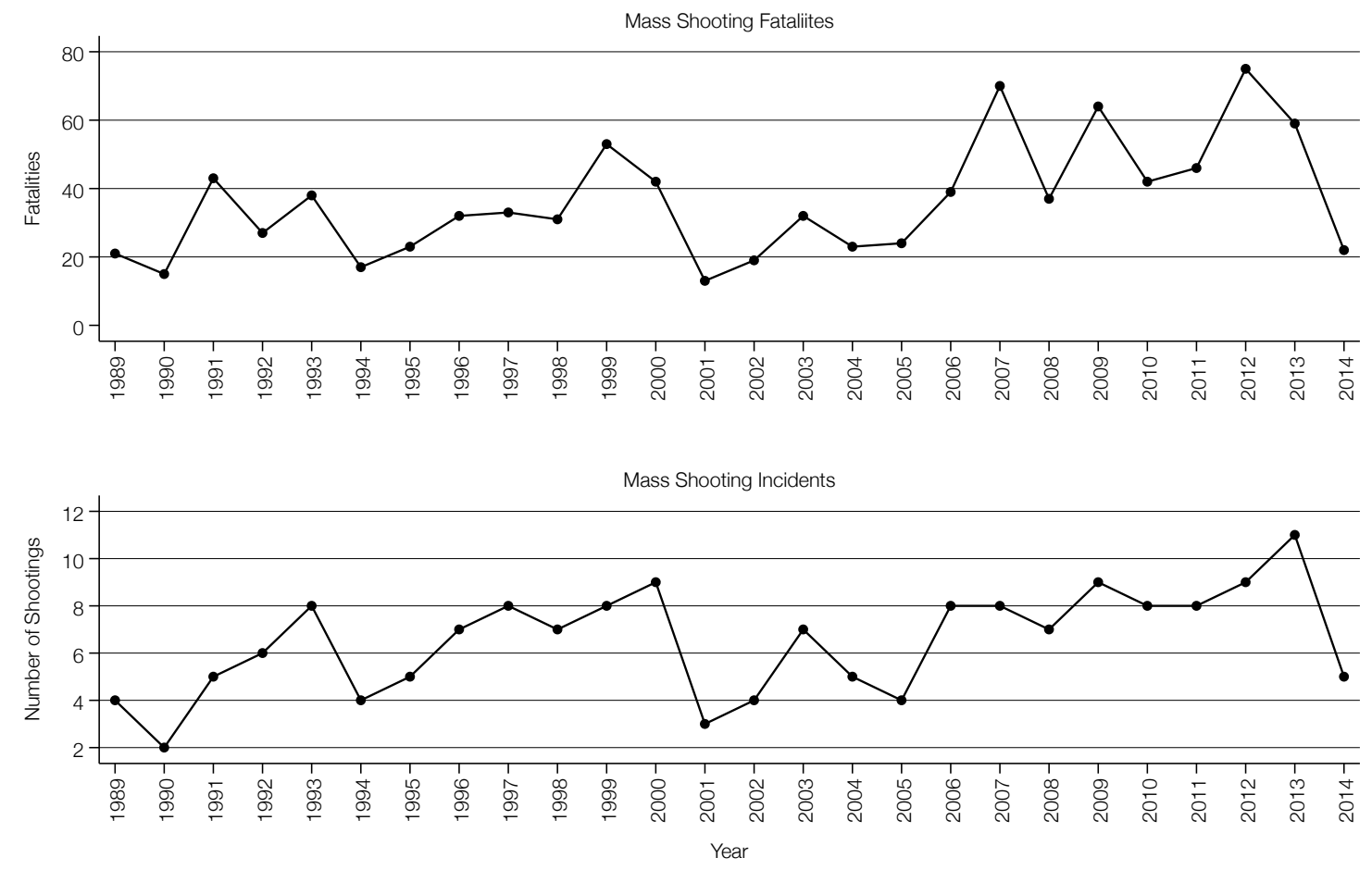

Figure 1 Mass shooting incidents and fatalities by year, 1989-2014. The upper panel shows the number of fatalities in mass shootings in which at least 3 people not related or romantically connected to the shooter were killed. The bottom panel shows the number of these incidents. Washington, D.C. is not included in the sample. 


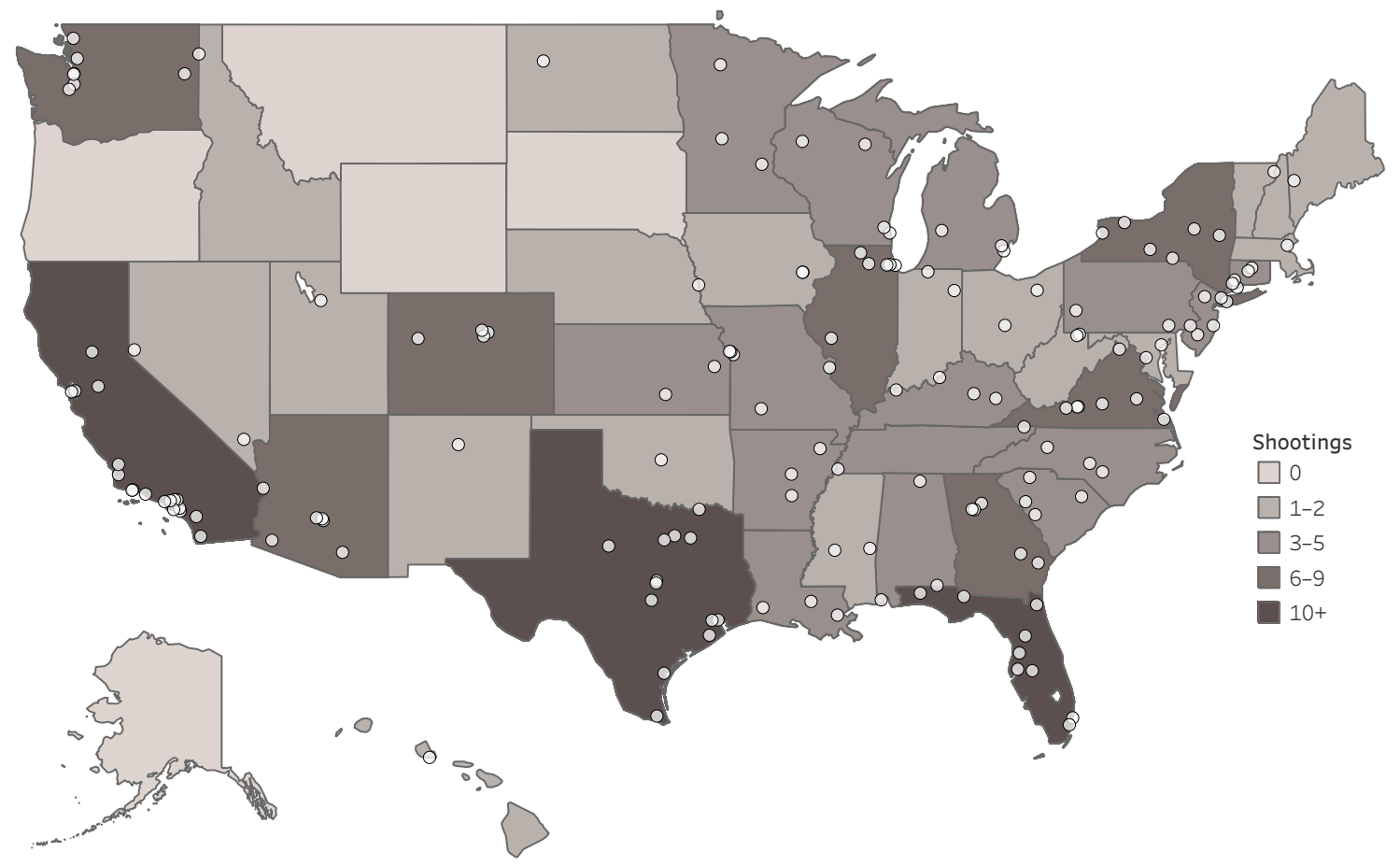

Figure 2 Locations of public mass shootings in the United States, 1989-2014. States are shaded based on the total number of shootings during the sample period. Points represent the locations of events. 


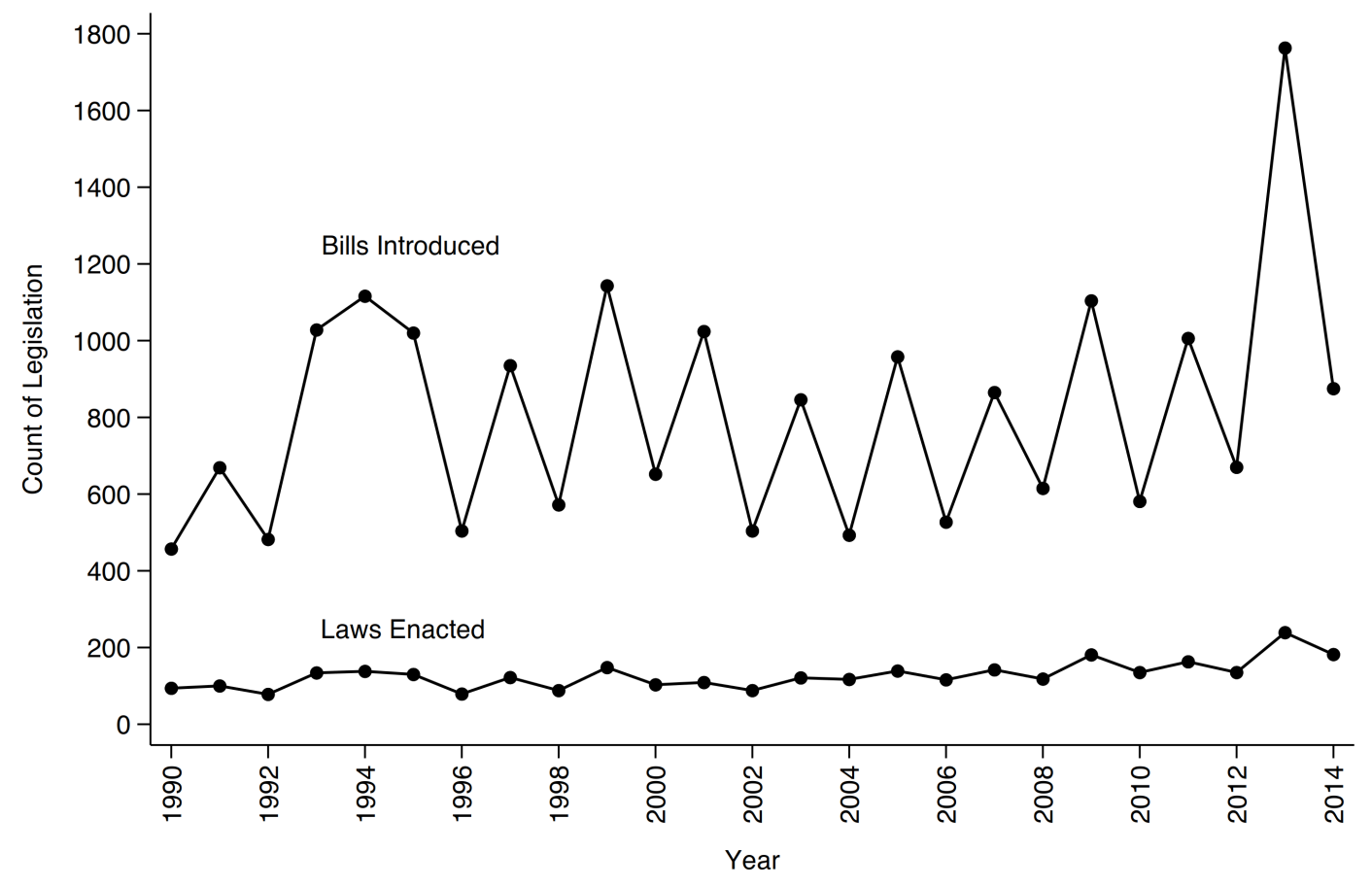

Figure 3 Total gun bills introduced and laws enacted by year, 1990-2014. 
Bills Introduced

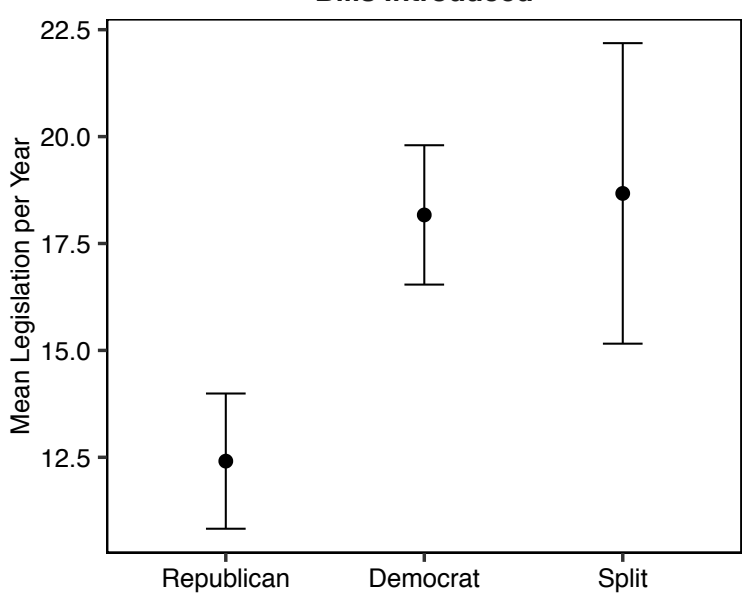

Tightening Laws

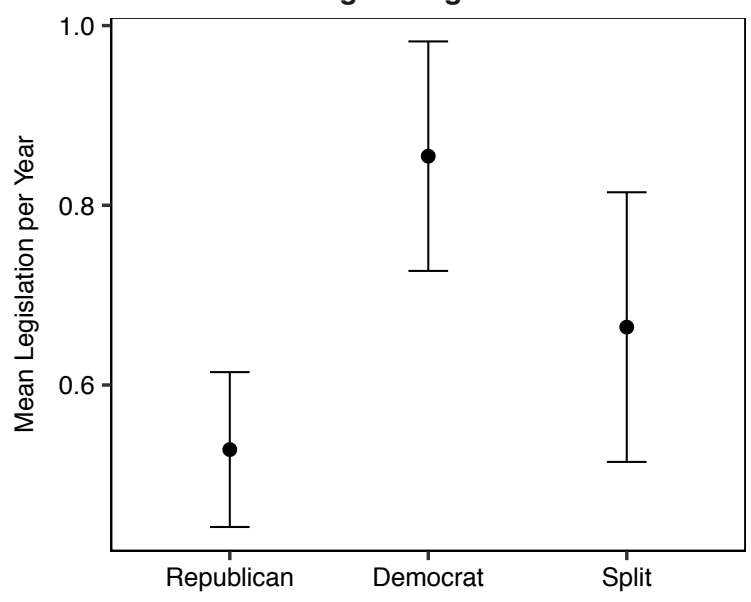

Laws Passed

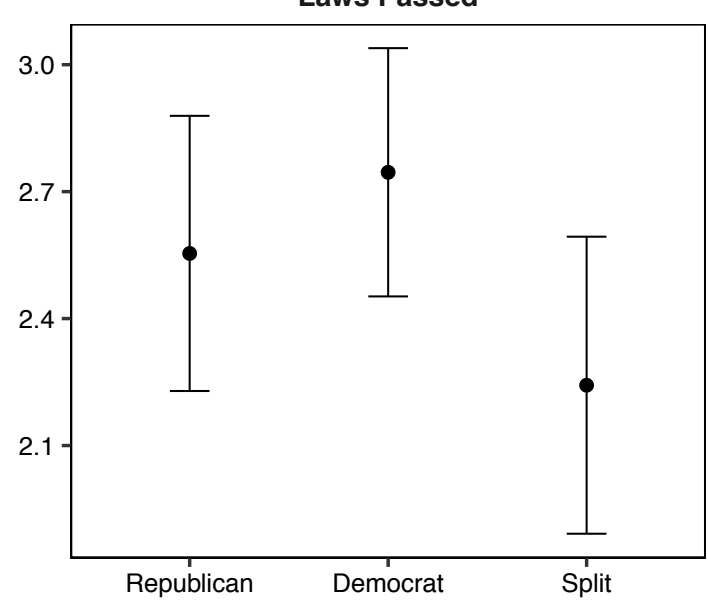

Loosening Laws

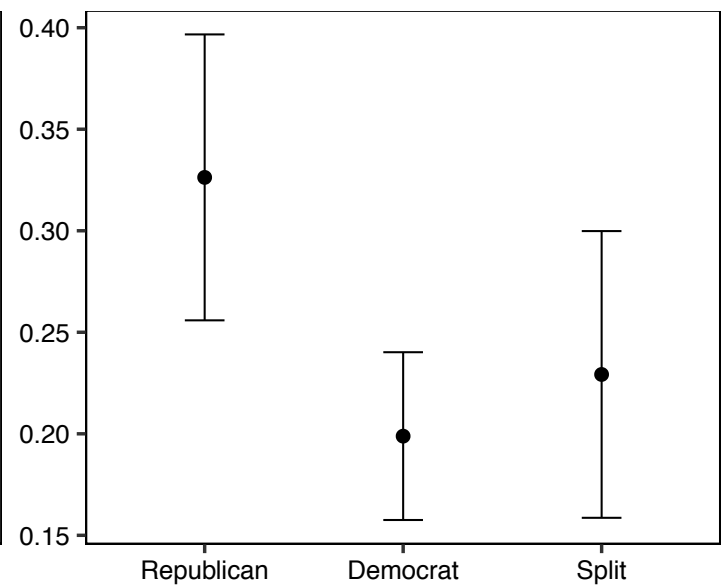

Figure 4 Comparison of annual legislation introduced by political party. Points represent the mean and lines are $95 \%$ confidence intervals. Legislature control means one political party includes both chambers of the legislature. The counts of tightening and loosening laws are based on laws with coder agreement (see section 2.2 of text). 


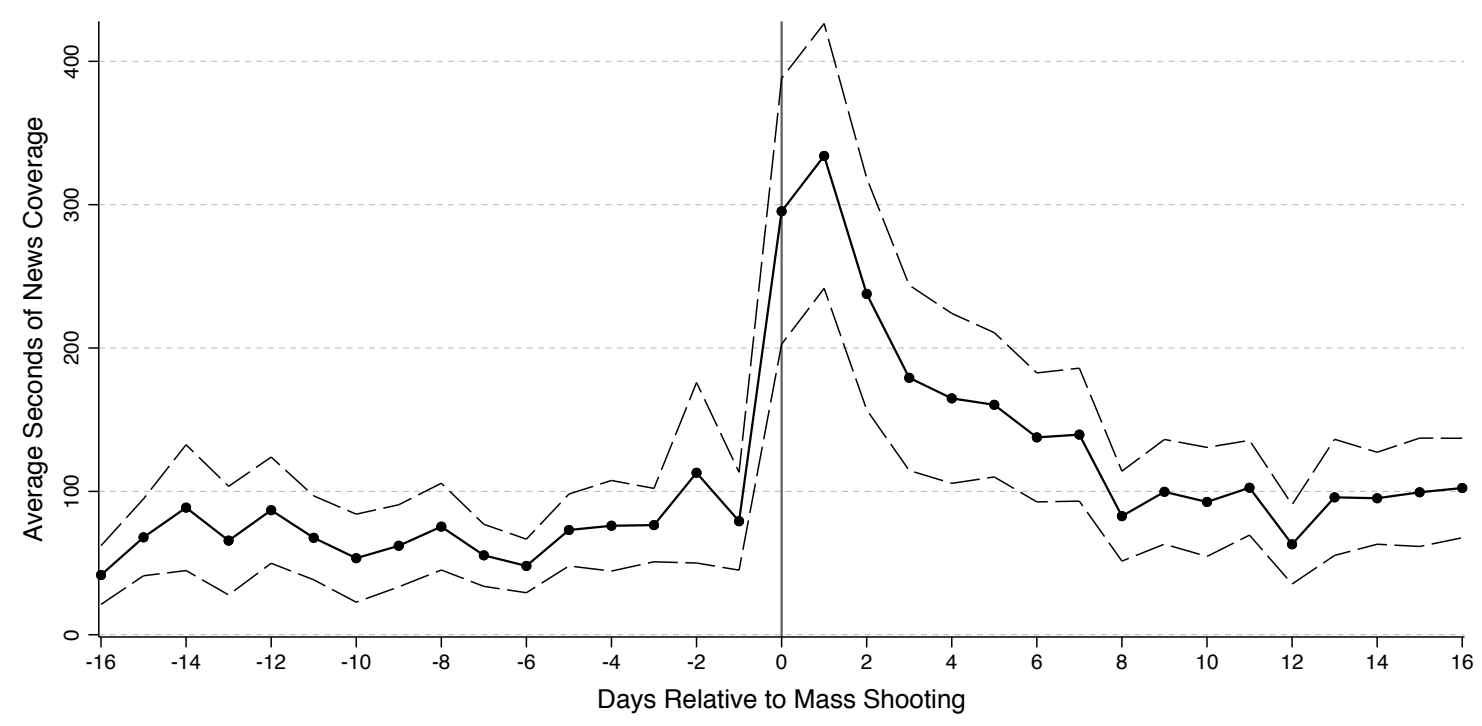

(a) Coverage around time of mass shootings

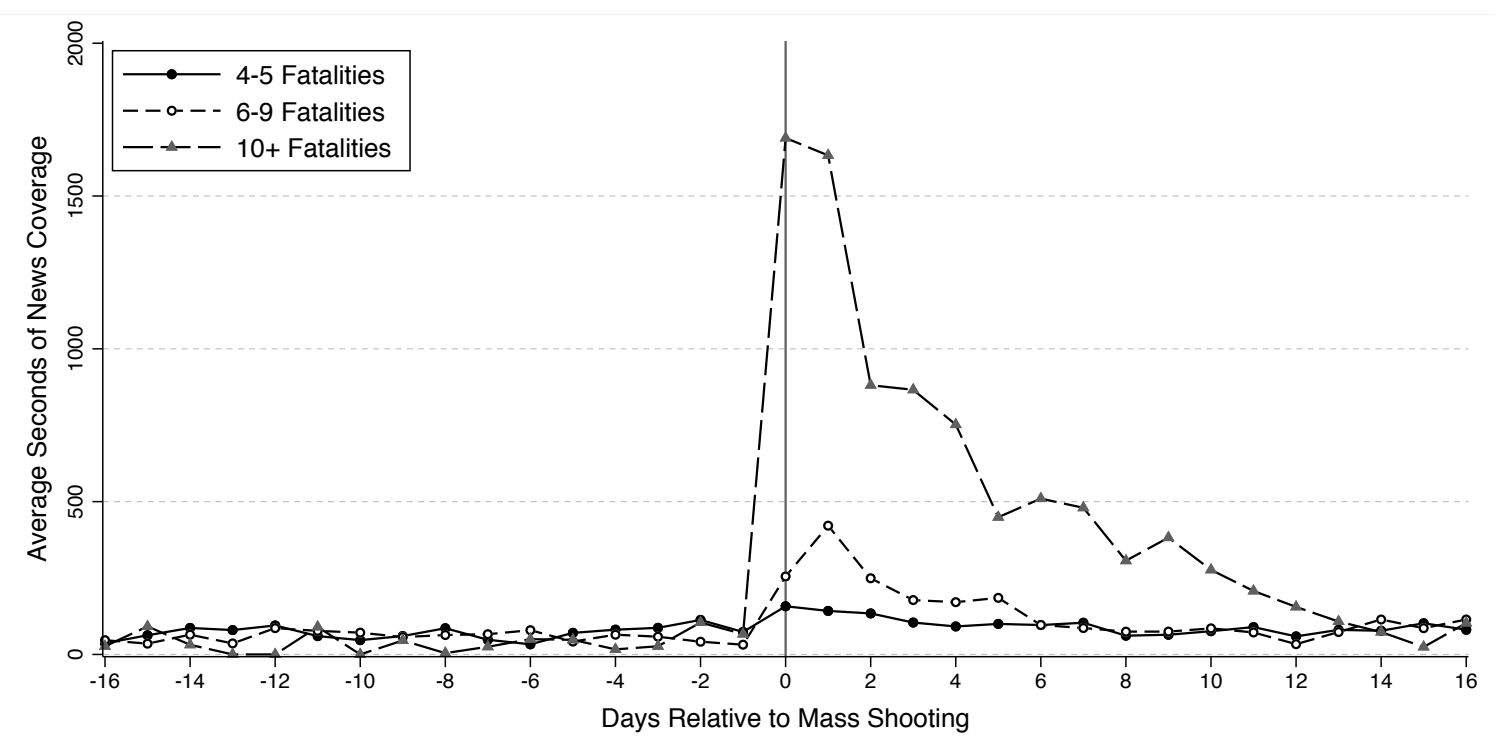

(b) Coverage by number of fatalities

Figure 5 Evening news coverage related to guns before and after mass shootings. Panel (a) shows average coverage around the time of all mass shootings; panel (b) shows coverage around the time of shootings by the number of fatalities caused. News coverage is measured in seconds. 


\section{Tables}

Table 1: Summary Statistics

\begin{tabular}{|c|c|c|c|c|c|c|c|}
\hline & mean & sd & p5 & p10 & p50 & p90 & p95 \\
\hline \multicolumn{8}{|l|}{ Gun Legislation } \\
\hline Bills introduced & 16.33 & 22.04 & 0 & 1 & 10 & 38 & 53 \\
\hline Laws enacted & 2.56 & 3.35 & 0 & 0 & 1 & 6 & 9 \\
\hline Tightening laws & 0.70 & 1.29 & 0 & 0 & 0 & 2 & 3 \\
\hline Loosening laws & 0.25 & 0.62 & 0 & 0 & 0 & 1 & 1 \\
\hline \multicolumn{8}{|l|}{ Gun Violence and Media } \\
\hline Mass shooting & 0.12 & 0.32 & 0 & 0 & 0 & 1 & 1 \\
\hline Fatalities & 0.72 & 2.40 & 0 & 0 & 0 & 4 & 5 \\
\hline Gun homicide rate & 3.76 & 2.55 & 0.72 & 0.98 & 3.42 & 7.40 & 8.65 \\
\hline News coverage & 0.06 & 0.34 & 0 & 0 & 0 & 0.06 & 0.29 \\
\hline \multicolumn{8}{|l|}{ Political Controls } \\
\hline Democratic legislature & 0.42 & 0.49 & 0 & 0 & 0 & 1 & 1 \\
\hline Republican legislature & 0.34 & 0.47 & 0 & 0 & 0 & 1 & 1 \\
\hline Republican governor & 0.53 & 0.50 & 0 & 0 & 1 & 1 & 1 \\
\hline \multicolumn{8}{|l|}{ Institutional Controls } \\
\hline Regular session & 0.94 & 0.24 & 0 & 1 & 1 & 1 & 1 \\
\hline First year of biennium & 0.48 & 0.50 & 0 & 0 & 0 & 1 & 1 \\
\hline \multicolumn{8}{|l|}{ Demographic Controls } \\
\hline Elderly $(65+) \%$ & 12.9 & 2.0 & 9.8 & 10.7 & 13.1 & 15.2 & 15.7 \\
\hline Under $25 \%$ & 35.1 & 2.7 & 31.4 & 32.2 & 34.8 & 38.0 & 39.5 \\
\hline Black \% & 10.3 & 9.5 & 0.6 & 0.8 & 7.4 & 26.4 & 30.1 \\
\hline Hispanic \% & 8.3 & 9.2 & 0.8 & 1.2 & 5.1 & 20.3 & 29.9 \\
\hline Unemployment \% & 5.7 & 1.9 & 3.1 & 3.5 & 5.4 & 8.1 & 9.3 \\
\hline Income per capita & 19.1 & 3.3 & 14.1 & 15.0 & 18.7 & 23.3 & 25.8 \\
\hline High school \% & 85.2 & 5.2 & 75.7 & 78.4 & 86.1 & 91.2 & 92.0 \\
\hline Veteran \% & 11.8 & 2.4 & 7.9 & 8.8 & 11.8 & 15.0 & 16.1 \\
\hline Divorce \% & 11.8 & 1.8 & 8.9 & 9.5 & 11.8 & 14.1 & 14.7 \\
\hline
\end{tabular}

Note: Sample includes 1,250 state-year observations from 1990 to 2014 . Bills introduced is the number of bills introduced in the legislature; Laws enacted is the number of bills that became law. Tightening and Loosening laws are numbers of enacted laws that tightened and loosened gun control respectively. Mass shooting is an indicator for state-years with a mass shooting in which three or more people not romantically involved with or related to the shooter(s) were killed. Fatalities is the total number of deaths in mass shootings in a state-year. The Gun homicide rate is expressed as deaths per 100,000 residents. News coverage is the hours of nightly news coverage of mass shootings occurring in a state. Democratic and Republican legislature are indicators for party control of the state legislature. Republican governor is an indicator for Republican governors. Regular session indicates whether the legislature convened a regular (as opposed to special) session to consider bills; some state legislatures only meet every other year. First year of biennium is an indicator for the first year of the two-year legislative biennium (the calendar year immediately following elections). Income per capita is measured in thousands of 1987 U.S. dollars. Other demographic variables are percentages. 
Table 2: The Effect of Mass Shootings on Gun Bill Introductions

\begin{tabular}{|c|c|c|c|c|c|c|c|c|}
\hline \multicolumn{9}{|c|}{ Dependent variable: number of firearm-related bills introduced in state legislature. } \\
\hline & (1) & (2) & (3) & (4) & (5) & (6) & (7) & (8) \\
\hline Mass Shooting & $\begin{array}{c}0.145^{* *} \\
(0.071)\end{array}$ & $\begin{array}{l}0.153^{* *} \\
(0.070)\end{array}$ & $\begin{array}{c}0.198 * \\
(0.101)\end{array}$ & $\begin{array}{l}0.143 * * \\
(0.069)\end{array}$ & & & & \\
\hline Fatalities & & & & & $\begin{array}{l}0.023 * * * \\
(0.008)\end{array}$ & $\begin{array}{l}0.024 * * * \\
(0.007)\end{array}$ & $\begin{array}{l}0.030 * * * \\
(0.011)\end{array}$ & $\begin{array}{l}0.023 * * * \\
(0.007)\end{array}$ \\
\hline Regular Session & $\begin{array}{l}1.581 * * * \\
(0.389)\end{array}$ & $\begin{array}{l}1.572 * * * \\
(0.394)\end{array}$ & $\begin{array}{c}-0.201 * \\
(0.115)\end{array}$ & $\begin{array}{l}1.573 * * * \\
(0.411)\end{array}$ & $\begin{array}{l}1.596 * * * \\
(0.378)\end{array}$ & $\begin{array}{l}1.586 * * * \\
(0.384)\end{array}$ & $\begin{array}{c}-0.181 \\
(0.118)\end{array}$ & $\begin{array}{l}1.580 * * * \\
(0.401)\end{array}$ \\
\hline First Year of Biennium & $\begin{array}{l}0.464 * * * \\
(0.125)\end{array}$ & $\begin{array}{l}0.462^{* * *} \\
(0.128)\end{array}$ & $\begin{array}{r}0.031 \\
(0.086)\end{array}$ & $\begin{array}{l}0.462 * * * \\
(0.131)\end{array}$ & $\begin{array}{l}0.457^{* * *} \\
(0.133)\end{array}$ & $\begin{array}{l}0.453^{* * *} \\
(0.137)\end{array}$ & $\begin{array}{r}0.051 \\
(0.087)\end{array}$ & $\begin{array}{l}0.454 * * * \\
(0.140)\end{array}$ \\
\hline Democratic Legislature & & $\begin{array}{r}-0.130 \\
(0.087)\end{array}$ & $\begin{array}{r}-0.068 \\
(0.076)\end{array}$ & $\begin{array}{c}-0.052 \\
(0.062)\end{array}$ & & $\begin{array}{r}-0.126 \\
(0.090)\end{array}$ & $\begin{array}{r}-0.057 \\
(0.076)\end{array}$ & $\begin{array}{r}-0.055 \\
(0.065)\end{array}$ \\
\hline Republican Legislature & & $\begin{array}{r}0.078 \\
(0.075)\end{array}$ & $\begin{array}{r}0.119 \\
(0.535)\end{array}$ & $\begin{array}{r}0.030 \\
(0.042)\end{array}$ & & $\begin{array}{r}0.082 \\
(0.075)\end{array}$ & $\begin{array}{r}0.134 \\
(0.556)\end{array}$ & $\begin{array}{r}0.032 \\
(0.044)\end{array}$ \\
\hline Republican Governor & & $\begin{array}{r}-0.025 \\
(0.066) \\
\end{array}$ & $\begin{array}{l}0.629 * * * \\
(0.222)\end{array}$ & $\begin{array}{r}-0.051 \\
(0.057) \\
\end{array}$ & & $\begin{array}{r}-0.019 \\
(0.065) \\
\end{array}$ & $\begin{array}{l}0.630 * * * \\
(0.223)\end{array}$ & $\begin{array}{r}-0.042 \\
(0.054) \\
\end{array}$ \\
\hline Demographic Controls & No & No & No & Yes & No & No & No & Yes \\
\hline State Fixed Effects & Yes & Yes & Yes & Yes & Yes & Yes & Yes & Yes \\
\hline Year Fixed Effects & Yes & Yes & $\mathrm{Yes}^{+}$ & Yes & Yes & Yes & $\mathrm{Yes}^{+}$ & Yes \\
\hline State-Specific Trends & No & No & No & Yes & No & No & No & Yes \\
\hline Observations & 1,250 & 1,250 & 650 & 1,250 & 1,250 & 1,250 & 650 & 1,250 \\
\hline
\end{tabular}


Table 3: Comparing Mass Shootings and Non-Mass Shootings

\begin{tabular}{lcccc}
\hline Dependent variable: number of firearm-related bills & introduced in state legislature. & \\
& $(\mathbf{1})$ & $\mathbf{( 2 )}$ & $\mathbf{( 3 )}$ & $\mathbf{( 4 )}$ \\
\hline Mass Shooting Fatalities / 100,000 & $1.339^{* * *}$ & $1.355^{* * *}$ & $1.952 * * *$ & $1.427 * * *$ \\
& $(0.212)$ & $(0.207)$ & $(0.385)$ & $(0.221)$ \\
& 0.014 & 0.013 & 0.012 & 0.011 \\
Ordinary Gun Homicides / 100,000 & $(0.031)$ & $(0.035)$ & $(0.037)$ & $(0.048)$ \\
& $1.559 * * *$ & $1.548 * * *$ & 0.125 & 1.541 \\
Regular Session & $(0.390)$ & $(0.397)$ & $(0.566)$ & $(0.415)$ \\
& $0.455^{* * *}$ & $0.452^{* * *}$ & $0.599^{* * *}$ & $0.454 * * *$ \\
First Year of Biennium & $(0.131)$ & $(0.134)$ & $(0.217)$ & $(0.136)$ \\
& & -0.119 & -0.177 & -0.049 \\
Democratic Legislature & & $(0.090)$ & $(0.116)$ & $(0.063)$ \\
& & 0.084 & 0.052 & $0.030 * * *$ \\
Republican Legislature & & $(0.071)$ & $(0.082)$ & $(0.041)$ \\
& & -0.016 & -0.056 & -0.032 \\
Republican Governor & & $(0.066)$ & $(0.077)$ & $(0.050)$ \\
& No & No & No & Yes \\
\hline Demographic Controls & Yes & Yes & Yes & Yes \\
State Fixed Effects & Yes & Yes & Yes & Yes \\
Year Fixed Effects & No & No & No & Yes \\
State-Specific Trends & 1,250 & 1,250 & 650 & 1,250 \\
Observations &
\end{tabular}

Note: Robust standard errors clustered by state in parentheses. Stars following coefficients represent $p$-values less than $.10\left({ }^{*}\right), .05(* *)$ and $.01(* * *)$. Mass Shooting Fatalities $/ 100,000$ is the number of deaths in mass shootings per 100,000 state residents. Ordinary Gun Homicides / 100,000 is the number of gun homicides not in mass shootings per 100,000 state residents. See note to Table 1 for other variable definitions.

${ }^{+}$Sample collapsed to two-year intervals and year effects replaced with two-year interval fixed effects. 
Table 4: Mass Shootings, Bills, and Laws by Political Party

\begin{tabular}{|c|c|c|c|c|}
\hline \multicolumn{5}{|c|}{$\begin{array}{r}\text { Dependent variable: number of firearm-related bills introduced } \\
\text { Bills Introduced }\end{array}$} \\
\hline & (1) & (2) & (3) & (4) \\
\hline \multirow[t]{2}{*}{ Dem. Leg. $\times$ Shooting } & 0.116 & 0.104 & 0.079 & 0.073 \\
\hline & $(0.080)$ & $(0.080)$ & $(0.101)$ & (0.109) \\
\hline \multirow[t]{2}{*}{ Rep. Leg. $\times$ Shooting } & $0.393 * * *$ & $0.402 * * *$ & $0.307 * * *$ & $0.283 * * *$ \\
\hline & $(0.147)$ & $(0.130)$ & $(0.100)$ & $(0.100)$ \\
\hline \multirow[t]{2}{*}{ Split Leg. $\times$ Shooting } & 0.026 & 0.007 & -0.120 & -0.112 \\
\hline & $(0.072)$ & $(0.063)$ & $(0.099)$ & $(0.097)$ \\
\hline \multirow[t]{2}{*}{ Democratic Legislature } & -0.149 & -0.070 & -0.064 & -0.022 \\
\hline & $(0.095)$ & $(0.067)$ & $(0.086)$ & $(0.104)$ \\
\hline \multirow[t]{2}{*}{ Republican Legislature } & 0.021 & -0.031 & $0.190 * *$ & $0.155 *$ \\
\hline & $(0.080)$ & $(0.054)$ & $(0.094)$ & $(0.092)$ \\
\hline \multirow[t]{2}{*}{ Republican Governor } & -0.026 & -0.049 & 0.016 & -0.049 \\
\hline & $(0.065)$ & $(0.054)$ & $(0.046)$ & $(0.051)$ \\
\hline \multirow[t]{2}{*}{ Regular Session } & $1.614 * * *$ & $1.626 * * *$ & $3.424 * * *$ & $3.474 * * *$ \\
\hline & $(0.372)$ & $(0.387)$ & $(0.792)$ & $(0.781)$ \\
\hline \multirow[t]{2}{*}{ First Year of Biennium } & $0.468 * * *$ & $0.468 * * *$ & 0.040 & 0.032 \\
\hline & $(0.124)$ & $(0.127)$ & $(0.056)$ & $(0.053)$ \\
\hline Demographic Controls & No & Yes & No & Yes \\
\hline State Fixed Effects & Yes & Yes & Yes & Yes \\
\hline Year Fixed Effects & Yes & Yes & Yes & Yes \\
\hline State-Specific Trends & No & Yes & No & Yes \\
\hline Observations & 1,250 & 1,250 & 1,250 & 1,250 \\
\hline
\end{tabular}

Note: Robust standard errors clustered by state in parentheses. Stars following coefficients represent $p$-values less than $.10(*), .05(* *)$ and $.01(* * *)$. The omitted group in all models is states without a mass shooting. See note to Table 1 for all variable definitions. 
Table 5: Mass Shootings and Enacted Laws

\begin{tabular}{|c|c|c|c|c|c|c|c|c|}
\hline & \multicolumn{4}{|c|}{ Tightening Laws } & \multicolumn{4}{|c|}{ Loosening Laws } \\
\hline & (1) & (2) & (3) & (4) & (5) & (6) & (7) & (8) \\
\hline \multirow[t]{2}{*}{ Mass Shooting } & -0.057 & -0.050 & & & $0.282 *$ & 0.258 & & \\
\hline & $(0.100)$ & $(0.103)$ & & & $(0.171)$ & $(0.171)$ & & \\
\hline \multirow[t]{2}{*}{ Dem. Leg. $\times$ Shooting } & & & -0.014 & 0.007 & & & -0.213 & -0.245 \\
\hline & & & $(0.134)$ & $(0.141)$ & & & $(0.371)$ & $(0.389)$ \\
\hline \multirow[t]{2}{*}{ Rep. Leg. $\times$ Shooting } & & & -0.003 & 0.002 & & & $0.853 * * *$ & $0.800 * * *$ \\
\hline & & & $(0.240)$ & $(0.236)$ & & & $(0.261)$ & $(0.259)$ \\
\hline \multirow[t]{2}{*}{ Split Leg. $\times$ Shooting } & & & -0.223 & -0.247 & & & 0.098 & 0.137 \\
\hline & & & $(0.256)$ & $(0.261)$ & & & $(0.341)$ & $(0.339)$ \\
\hline \multirow[t]{2}{*}{ Democratic Legislature } & 0.066 & 0.102 & 0.034 & 0.063 & -0.232 & -0.293 & -0.191 & -0.233 \\
\hline & $(0.141)$ & $(0.148)$ & $(0.162)$ & $(0.170)$ & $(0.195)$ & $(0.202)$ & $(0.225)$ & $(0.226)$ \\
\hline \multirow[t]{2}{*}{ Republican Legislature } & 0.193 & 0.157 & 0.161 & 0.120 & $0.497 * * *$ & $0.497 * * *$ & $0.384 *$ & $0.391 *$ \\
\hline & $(0.147)$ & $(0.136)$ & $(0.155)$ & $(0.145)$ & (0.189) & $(0.187)$ & $(0.212)$ & $(0.213)$ \\
\hline \multirow[t]{2}{*}{ Republican Governor } & -0.024 & -0.050 & -0.023 & -0.050 & -0.118 & -0.098 & -0.101 & -0.079 \\
\hline & $(0.081)$ & $(0.084)$ & $(0.080)$ & $(0.083)$ & $(0.167)$ & $(0.171)$ & $(0.163)$ & $(0.167)$ \\
\hline \multirow[t]{2}{*}{ Regular Session } & $3.231 * * *$ & $3.221 * * *$ & $3.237 * * *$ & $3.226 * * *$ & $16.615^{* * *}$ & $16.248 * * *$ & $16.290 * * *$ & $15.550 * * *$ \\
\hline & $(0.770)$ & $(0.778)$ & $(0.771)$ & $(0.779)$ & $(0.457)$ & $(0.462)$ & $(0.454)$ & $(0.466)$ \\
\hline \multirow[t]{2}{*}{ First Year of Biennium } & 0.016 & 0.032 & 0.021 & 0.037 & $0.421 * * *$ & $0.414 * * *$ & $0.463 * * *$ & $0.455^{* * *}$ \\
\hline & $(0.109)$ & $(0.112)$ & $(0.110)$ & $(0.112)$ & $(0.132)$ & $(0.136)$ & $(0.175)$ & $(0.175)$ \\
\hline Demographic Controls & No & Yes & No & Yes & No & Yes & No & Yes \\
\hline State Fixed Effects & Yes & Yes & Yes & Yes & Yes & Yes & Yes & Yes \\
\hline Year Fixed Effects & Yes & Yes & Yes & Yes & Yes & Yes & Yes & Yes \\
\hline Observations & 1,250 & 1,250 & 1,250 & 1,250 & 1,175 & 1,175 & 1,175 & 1,175 \\
\hline
\end{tabular}

Note: Robust standard errors clustered by state in parentheses. Stars following coefficients represent $p$-values less than $.10(*), .05(* *)$ and $.01(* * *)$. Models $3-4$ and $7-8$ show the effect of mass shootings in Republican, Democratic, and split legislatures; the omitted group in these models is states without a mass shooting. See note to Table 1 for all variable definitions. 
Table 6: News Coverage and Bill Introductions

\begin{tabular}{lcccc}
\hline Dependent variable: number of firearm-related bills & introduced in state legislature. & \\
& $(\mathbf{1})$ & $\mathbf{( 2 )}$ & $\mathbf{( 3 )}$ & $\mathbf{( 4 )}$ \\
\hline Mass Shooting $\times$ News Coverage & $0.125^{* * *}$ & $0.126^{* * *}$ & $0.069 *$ & $0.127 * *$ \\
& $(0.041)$ & $(0.040)$ & $(0.037)$ & $(0.054)$ \\
Mass Shooting & 0.070 & 0.078 & 0.128 & 0.067 \\
& $(0.078)$ & $(0.077)$ & $(0.119)$ & $(0.076)$ \\
Regular Session & $1.582 * * *$ & $1.573^{* * *}$ & 0.135 & $1.570 * * *$ \\
& $(0.385)$ & $(0.390)$ & $(0.538)$ & $(0.406)$ \\
First Year of Biennium & $0.456 * * *$ & $0.453^{* * *}$ & $0.621^{* * *}$ & $0.454 * *$ \\
& $(0.129)$ & $(0.132)$ & $(0.218)$ & $(0.135)$ \\
Democratic Legislature & & -0.129 & $-0.196 *$ & -0.055 \\
& & $(0.089)$ & $(0.117)$ & $(0.064)$ \\
Republican Legislature & & 0.080 & 0.035 & 0.030 \\
& & $(0.075)$ & $(0.087)$ & $(0.043)$ \\
Republican Governor & & -0.020 & -0.062 & -0.042 \\
& & $(0.066)$ & $(0.076)$ & $(0.056)$ \\
\hline Demographic Controls & No & No & No & Yes \\
State Fixed Effects & Yes & Yes & Yes & Yes \\
Year Fixed Effects & Yes & Yes & Yes & Yes \\
State-Specific Trends & No & No & No & Yes \\
Observations & 1,250 & 1,250 & 650 & 1,250 \\
\hline
\end{tabular}

Note: Robust standard errors clustered by state in parentheses. Stars following coefficients represent $p$-values less than $.10\left({ }^{*}\right), .05(* *)$ and $.01(* * *)$. News Coverage does not appear by itself in the model because we only have data from the national nightly news; the coefficient is therefore absorbed by the year fixed effects. See note to Table 1 for variable definitions.

${ }^{\dagger}$ Sample collapsed to two-year intervals and year effects replaced with two-year interval fixed effects. 


\section{Appendix A: Coding Gun Laws}

This appendix provides examples of coding bills and further investigates coder agreement with our gold standard when deciding whether bills tighten or loosen gun control. As explained in the text, a law can be one of the following five types:

- Tightening (stricter gun control)

- Loosening (weaker gun control)

- Uncertain (insufficient information)

- Both tightening and loosening

- Neutral (neither tightening nor loosening)

Table A1 presents examples of each type and illustrates how coders assigned laws to each category. Table A2 shows the categorization of the gun laws in our sample based on the above coding scheme. Coders agree on the type of law about 52 percent of the time; about half of these laws tighten restrictions on guns and about 20 percent loosen restrictions on guns. The remainder are uncertain, neutral, or both tightened and loosened gun policy.

Table A3 shows the frequency of coder responses for bills we classified as tightening or loosening in the gold standard. The most common response is both coders agreeing with the gold standard. When coders to not agree with the gold standard, it is common for at least one coder to supply the right answer and the other coder to be either uncertain or think the bill both tightens and loosens gun control.

The following is an example of a law that tighten gun control, which coders got wrong:

"Increases the penalties for carrying a concealed deadly weapon, when the weapon is a firearm, by reclassifying what is currently a class $G$ felony as a class $D$ violent felony; deletes a penalty provision that is unnecessary and duplicative, since any person previously convicted of a violation of section 1442 is also a person prohibited under section 1448 of Title 11." 
Coders may have seen "deletes a penalty provision" and assumed the law also loosened gun control because they did not read that the provision was "unnecessary and duplicative." The following is an example of a law loosening gun control, which coders got wrong:

"Bars a county or municipality from filing a lawsuit against the manufacturer of firearms or ammunition under certain circumstances; reserves an exclusive right for the State to maintain such an action; repeals conflicting laws."

Some coders made the mistake of thinking this bill both loosened and tightened gun control, perhaps because "bars" sounds like it relates to tightening and "repeals" sounds like it relates to loosening. Both of these are fairly long synopses; however, the share of coder pairs that supply the right answer is not correlated with the length of the synopsis. 
Table A1: Example of Coding Gun Laws

id summary

1 Creates a new felony for firing a gun within

1

0

0

Reduces the age limit for purchase of a handgun
from 21 to 18 .

3 Allows parole officers to carry a loaded

3 firearm while commuting to and from work.

Relates to the use of firearms in state parks
and campgrounds. $\quad \begin{aligned} & 0 \\ & \text { Requires a license to operate a gun show. } \\ & \begin{array}{l}\text { Eliminates the waiting period for firearm sales } \\ \text { if the purchaser has a valid permit to carry a } \\ \text { concealed weapon. }\end{array}\end{aligned}$

Note: Table shows examples of coding gun laws based on bill summaries. Coders were given a full manual to explain the meaning of "tighten", "loosen", "neutral," and "uncertain" along with the following examples. This table mimics the appearance of the Excel workbooks used by the coders. The first bill creates a new crime related to firearms. It tightens restrictions on firearms. The second bill makes it easier for people to acquire guns; it loosens restrictions on firearms. The third bill is exclusively about parole officers; it is neutral because it does not affect the general public. The fourth bill is uncertain because the summary is a generic description that does not specify whether the law tightens or loosens restrictions on firearms. The fifth bill both tightens and loosens; it regulates gun shows, but also eliminates a restriction on firearm purchasers.

Table A2: Results of Coding Gun Laws

\begin{tabular}{lrr}
\hline Category & Total Laws & Percent of Total \\
\hline Coders agree & & \\
Tightening & 872 & 27.3 \\
Loosening & 312 & 9.8 \\
Uncertain & 245 & 7.7 \\
Both (Tighten and Loosen) & 79 & 2.5 \\
Neutral & 173 & 5.4 \\
Coders disagree & 1,518 & 47.5 \\
\hline Total & 3,199 & 100.0 \\
\hline
\end{tabular}


Table A3: Coder Agreement with Tightening/Loosening Gold Standard

\begin{tabular}{|c|c|c|c|c|c|}
\hline & Neutral & Tighten & Loosen & Both & Uncertain \\
\hline \multicolumn{6}{|l|}{ Tighten } \\
\hline Neutral & 6 & 39 & 2 & 2 & 5 \\
\hline Tighten & & 460 & 11 & 53 & 61 \\
\hline Loosen & & & 0 & 2 & 0 \\
\hline Both & & & & 13 & 2 \\
\hline Uncertain & & & & & 30 \\
\hline \multicolumn{6}{|l|}{ Loosen } \\
\hline Neutral & 0 & 3 & 15 & 2 & 5 \\
\hline Tighten & & 12 & 45 & 7 & 15 \\
\hline Loosen & & & 337 & 72 & 29 \\
\hline Both & & & & 10 & 2 \\
\hline Uncertain & & & & & 8 \\
\hline
\end{tabular}

Note: Gold Standard-either tightening or loosening-in bold. Cell values represent the frequency of two coder responses across all unique pairs of coders who saw a given law. 


\section{Appendix B: Effect of Shootings in Neighboring States}

Table B1: Mass Shootings in Neighboring States, Bills and Laws

Dependent variable: number of firearm-related bills introduced or laws enacted in state.

\begin{tabular}{|c|c|c|c|c|c|c|c|c|}
\hline & \multicolumn{4}{|c|}{ Bills Introduced } & \multicolumn{4}{|c|}{ Laws Enacted } \\
\hline & (1) & (2) & (3) & (4) & (5) & (6) & (7) & (8) \\
\hline \multirow[t]{2}{*}{ Mass Shooting } & $0.142 * *$ & $0.146 *$ & & & 0.087 & 0.077 & & \\
\hline & $(0.071)$ & (0.079) & & & $(0.073)$ & $(0.086)$ & & \\
\hline \multirow[t]{2}{*}{ Neighbor Shooting } & -0.049 & & & & 0.050 & & & \\
\hline & $(0.051)$ & & & & $(0.056)$ & & & \\
\hline \multirow[t]{2}{*}{ Cen. Division Shooting } & & -0.005 & & & & 0.021 & & \\
\hline & & (0.041) & & & & (0.054) & & \\
\hline \multirow[t]{2}{*}{ Fatalities } & & & $0.023 * * *$ & $0.018 * *$ & & & 0.013 & 0.008 \\
\hline & & & $(0.007)$ & (0.009) & & & $(0.008)$ & (0.009) \\
\hline \multirow[t]{2}{*}{ Neighbor Fatalities } & & & -0.001 & & & & 0.002 & \\
\hline & & & $(0.004)$ & & & & $(0.004)$ & \\
\hline \multirow[t]{2}{*}{ Cen. Division Fatalities } & & & & 0.007 & & & & 0.006 \\
\hline & & & & $(0.005)$ & & & & $(0.005)$ \\
\hline Institutional Controls & Yes & Yes & Yes & Yes & Yes & Yes & Yes & Yes \\
\hline Political Controls & Yes & Yes & Yes & Yes & Yes & Yes & Yes & Yes \\
\hline Demographic Controls & Yes & Yes & Yes & Yes & Yes & Yes & Yes & Yes \\
\hline State Fixed Effects & Yes & Yes & Yes & Yes & Yes & Yes & Yes & Yes \\
\hline Year Fixed Effects & Yes & Yes & Yes & Yes & Yes & Yes & Yes & Yes \\
\hline State-Specific Trends & Yes & Yes & Yes & Yes & Yes & Yes & Yes & Yes \\
\hline Observations & 1,250 & 1,250 & 1,250 & 1,250 & 1,250 & 1,250 & 1,250 & 1,250 \\
\hline
\end{tabular}

Note: Robust standard errors clustered by state in parentheses. Stars following coefficients represent $p$-values less than $.10\left(^{*}\right), .05(* *)$ and $.01(* * *)$. Neighbor variables refer to states with a shared border; Cen. Division refers to states within the same Census division. See note to Table 1 for other variable definitions. 
Table B2: Mass Shootings in Neighboring States and Directions of Policy Change

Dependent variable: number of firearm-related laws enacted.

\begin{tabular}{|c|c|c|c|c|}
\hline & \multicolumn{2}{|c|}{ Tightening Laws } & \multicolumn{2}{|c|}{ Loosening Laws } \\
\hline & (1) & (2) & (3) & (4) \\
\hline \multirow[t]{2}{*}{ Dem. Leg. $\times$ Shooting } & 0.037 & -0.005 & -0.287 & -0.181 \\
\hline & $(0.136)$ & $(0.134)$ & $(0.364)$ & (0.399) \\
\hline \multirow[t]{2}{*}{ Rep. Leg. $\times$ Shooting } & 0.007 & -0.080 & $0.794 * * *$ & $0.894 * * *$ \\
\hline & $(0.223)$ & $(0.256)$ & $(0.263)$ & $(0.287)$ \\
\hline \multirow[t]{2}{*}{ Split Leg. $\times$ Shooting } & -0.275 & -0.092 & 0.136 & 0.080 \\
\hline & $(0.247)$ & (0.229) & (0.329) & (0.379) \\
\hline \multirow[t]{2}{*}{ Dem. Leg. $\times$ Neighbor Shooting } & 0.208 & & -0.061 & \\
\hline & $(0.139)$ & & $(0.242)$ & \\
\hline \multirow[t]{2}{*}{ Rep. Leg. $\times$ Neighbor Shooting } & $-0.266 * *$ & & 0.356 & \\
\hline & $(0.120)$ & & $(0.244)$ & \\
\hline \multirow[t]{2}{*}{ Split Leg. $\times$ Neighbor Shooting } & -0.163 & & -0.118 & \\
\hline & $(0.207)$ & & $(0.227)$ & \\
\hline \multirow[t]{2}{*}{ Dem. Leg. $\times$ Cen. Division Shooting } & & 0.157 & & -0.186 \\
\hline & & $(0.158)$ & & $(0.238)$ \\
\hline \multirow[t]{2}{*}{ Rep. Leg. $\times$ Cen. Division Shooting } & & 0.015 & & -0.118 \\
\hline & & $(0.108)$ & & $(0.174)$ \\
\hline \multirow[t]{2}{*}{ Split Leg. $\times$ Cen. Division Shooting } & & -0.254 & & 0.101 \\
\hline & & $(0.169)$ & & $(0.254)$ \\
\hline Political Controls & Yes & Yes & Yes & Yes \\
\hline Institutional Controls & Yes & Yes & Yes & Yes \\
\hline Demographic Controls & Yes & Yes & Yes & Yes \\
\hline State Fixed Effects & Yes & Yes & Yes & Yes \\
\hline Year Fixed Effects & Yes & Yes & Yes & Yes \\
\hline Observations & 1,250 & 1,250 & 1,175 & 1,175 \\
\hline
\end{tabular}

Note: Robust standard errors clustered by state in parentheses. Stars following coefficients represent $p$-values less than $.10(*), .05\left(^{* *}\right)$ and $.01\left(^{* * *}\right)$. Models show the effect of mass shootings in Republican, Democratic, and split legislatures; the omitted group in these models is states without a mass shooting. Neighbor variables refer to states with a shared border; Cen. Division refers to states within the same Census division. See note to Table 1 for other variable definitions. 
Appendix C: Laws Enacted

Table C1: Laws Enacted and Mass Shootings

\begin{tabular}{|c|c|c|c|c|c|c|c|c|}
\hline \multicolumn{9}{|c|}{ Dependent variable: number of firearm-related laws enacted in state. } \\
\hline & (1) & $(2)$ & (3) & (4) & (5) & (6) & (7) & (8) \\
\hline \multirow[t]{2}{*}{ Mass Shooting } & 0.078 & 0.099 & 0.112 & 0.089 & & & & \\
\hline & $(0.079)$ & (0.074) & (0.089) & $(0.075)$ & & & & \\
\hline \multirow[t]{2}{*}{ Fatalities } & & & & & 0.011 & 0.014 & 0.005 & 0.013 \\
\hline & & & & & (0.009) & (0.009) & (0.014) & $(0.008)$ \\
\hline \multirow[t]{2}{*}{ Regular Session } & $3.399 * * *$ & $3.392 * * *$ & 0.388 & $3.444 * * *$ & $3.401 * * *$ & $3.393^{* * *}$ & 0.373 & $3.443 * * *$ \\
\hline & $(0.766)$ & $(0.777)$ & $(0.716)$ & $(0.763)$ & $(0.772)$ & $(0.784)$ & $(0.715)$ & (0.769) \\
\hline \multirow[t]{2}{*}{ First Year of Biennium } & 0.037 & 0.028 & 0.203 & 0.022 & 0.028 & 0.017 & 0.178 & 0.012 \\
\hline & $(0.051)$ & $(0.051)$ & $(0.290)$ & $(0.050)$ & $(0.051)$ & $(0.051)$ & $(0.298)$ & $(0.051)$ \\
\hline \multirow[t]{2}{*}{ Democratic Legislature } & & -0.026 & -0.107 & 0.012 & & -0.022 & -0.103 & 0.011 \\
\hline & & (0.079) & $(0.093)$ & $(0.097)$ & & $(0.082)$ & $(0.088)$ & $(0.098)$ \\
\hline \multirow[t]{2}{*}{ Republican Legislature } & & $0.260 * * *$ & 0.168 & $0.218 * * *$ & & $0.266 * * *$ & $0.167 *$ & $0.223^{* * *}$ \\
\hline & & $(0.090)$ & $(0.103)$ & $(0.083)$ & & $(0.091)$ & $(0.100)$ & $(0.085)$ \\
\hline \multirow[t]{2}{*}{ Republican Governor } & & 0.010 & -0.039 & -0.055 & & 0.012 & -0.040 & -0.053 \\
\hline & & $(0.048)$ & $(0.050)$ & $(0.051)$ & & $(0.048)$ & $(0.053)$ & $(0.050)$ \\
\hline Demographic Controls & No & No & No & Yes & No & No & No & Yes \\
\hline State Fixed Effects & Yes & Yes & Yes & Yes & Yes & Yes & Yes & Yes \\
\hline Year Fixed Effects & Yes & Yes & $\mathrm{Yes}^{+}$ & Yes & Yes & Yes & Yes $^{\dagger}$ & Yes \\
\hline State-Specific Trends & No & No & No & Yes & No & No & No & Yes \\
\hline Observations & 1,250 & 1,250 & 650 & 1,250 & 1,250 & 1,250 & 650 & 1,250 \\
\hline
\end{tabular}

Note: Robust standard errors clustered by state in parentheses. Stars following coefficients represent $p$-values less than .10 $\left({ }^{*}\right), .05\left(^{* *}\right)$ and $.01\left(^{* * *}\right)$. Variables are identical to those in Table 2 , except for the dependent variable, which is the number of firearm-related laws enacted instead of the number of bills introduced. See note to Table 1 for variable definitions.

${ }^{+}$Sample collapsed to two-year intervals and year effects replaced with two-year interval fixed effects. 
Appendix D: Mass Shootings and Neutral Laws

Table D1. Neutral Laws Enacted

Dependent variable: number of neutral firearm-related laws enacted.

(1)

(2)

\begin{tabular}{lrr}
\hline Mass Shooting & 0.114 & \\
& $(0.195)$ & 0.042 \\
Dem. Leg. $\times$ Shooting & & $(0.299)$ \\
& & 0.206 \\
Rep. Leg. $\times$ Shooting & & $(0.381)$ \\
& & 0.142 \\
Split Leg. $\times$ Shooting & & $(0.322)$ \\
\hline Political Controls & Yes & Yes \\
Institutional Controls & Yes & Yes \\
Demographic Controls & Yes & Yes \\
State Fixed Effects & Yes & Yes \\
Year Fixed Effects & Yes & Yes \\
Observations & 1,050 & 1,050 \\
\hline
\end{tabular}

Note: Sample size differs from other tables due to states with all zero observations (i.e. no years with neutral laws enacted). 


\section{Appendix E: Media Coverage and Mass Shootings}

This appendix presents regression results showing that mass shootings are associated with large increases in gun-related news coverage and that increased news coverage is associated with greater legislative activity in the form of firearm-related bills introduced in state legislatures.

Table E1 shows results from regressing the log of each day's total seconds of gun-related news coverage on an indicator for the occurrence of a mass shooting and 10 lags of that indicator. The results suggest that media attention to guns increases roughly 300 percent immediately following a mass shooting and that coverage remains elevated from pre-shooting levels for at least a week following the event. Table E2 presents similar results using the count of mass shooting fatalities as the independent variable instead of a mass shooting indicator variable. ${ }^{17}$

\footnotetext{
${ }^{17}$ Additionally, we estimated models with 10 leads of each indicator variable (not shown to conserve space) and none of the leads are statistically significant at conventional levels. This suggests that gun-related media coverage does not presage mass shootings (as would be the case if media reports about firearms caused shootings or reflected other contemporary events associated with mass shootings).
} 
Table E1: Mass Shootings and News Coverage

\begin{tabular}{|c|c|c|c|c|}
\hline \multicolumn{5}{|c|}{ Dependent variable: $\log (1+$ Seconds of News Coverage $)$} \\
\hline Mass Shooting & $\begin{array}{l}1.509^{* * *} \\
(0.218)\end{array}$ & $\begin{array}{l}1.510^{* * *} \\
(0.220)\end{array}$ & $\begin{array}{l}1.497^{* * *} \\
(0.218)\end{array}$ & $\begin{array}{c}1.443^{* * *} \\
(0.214)\end{array}$ \\
\hline \multicolumn{5}{|c|}{ Lags of Mass Shooting (Days): } \\
\hline L1 & $\begin{array}{c}1.667^{* * *} \\
(0.226)\end{array}$ & $\begin{array}{c}1.656^{* * *} \\
(0.227)\end{array}$ & $\begin{array}{l}1.638^{* * *} \\
(0.226)\end{array}$ & $\begin{array}{c}1.584^{* * *} \\
(0.222)\end{array}$ \\
\hline L2 & & $\begin{array}{c}0.735^{* * *} \\
(0.225)\end{array}$ & $\begin{array}{c}0.729^{* * *} \\
(0.224)\end{array}$ & $\begin{array}{l}0.685^{* * *} \\
(0.223)\end{array}$ \\
\hline L3 & & $\begin{array}{c}0.728^{* * *} \\
(0.214)\end{array}$ & $\begin{array}{l}0.726^{* * *} \\
(0.213)\end{array}$ & $\begin{array}{l}0.684^{* * *} \\
(0.204)\end{array}$ \\
\hline L4 & & $\begin{array}{c}0.422^{* *} \\
(0.214)\end{array}$ & $\begin{array}{c}0.426^{* *} \\
(0.213)\end{array}$ & $\begin{array}{c}0.384^{*} \\
(0.207)\end{array}$ \\
\hline L5 & & $\begin{array}{c}0.844^{* * *} \\
(0.214)\end{array}$ & $\begin{array}{l}0.869^{* * *} \\
(0.214)\end{array}$ & $\begin{array}{l}0.832^{* * *} \\
(0.209)\end{array}$ \\
\hline L6 & & $\begin{array}{l}0.610^{* * *} \\
(0.206)\end{array}$ & $\begin{array}{l}0.620^{* * *} \\
(0.206)\end{array}$ & $\begin{array}{l}0.582^{* * *} \\
(0.194)\end{array}$ \\
\hline L7 & & $\begin{array}{c}0.466^{* *} \\
(0.208)\end{array}$ & $\begin{array}{c}0.453^{* *} \\
(0.207)\end{array}$ & $\begin{array}{c}0.419^{* *} \\
(0.202)\end{array}$ \\
\hline L8 & & $\begin{array}{r}0.255 \\
(0.196)\end{array}$ & $\begin{array}{r}0.237 \\
(0.195)\end{array}$ & $\begin{array}{r}0.194 \\
(0.185)\end{array}$ \\
\hline L9 & & $\begin{array}{r}0.260 \\
(0.197)\end{array}$ & $\begin{array}{r}0.254 \\
(0.197)\end{array}$ & $\begin{array}{r}0.212 \\
(0.187)\end{array}$ \\
\hline L10 & & $\begin{array}{r}0.302 \\
(0.194)\end{array}$ & $\begin{array}{r}0.300 \\
(0.195)\end{array}$ & $\begin{array}{r}0.258 \\
(0.185)\end{array}$ \\
\hline Constant & $\begin{array}{c}1.544^{* * *} \\
(0.025)\end{array}$ & $\begin{array}{c}1.463^{* * *} \\
(0.027)\end{array}$ & $\begin{array}{l}1.136^{* * *} \\
(0.060)\end{array}$ & $\begin{array}{l}0.897^{* * *} \\
(0.151)\end{array}$ \\
\hline \multicolumn{5}{|l|}{ Fixed Effects } \\
\hline Day-of-week & No & No & Yes & Yes \\
\hline Month & No & No & No & Yes \\
\hline Year & No & No & No & Yes \\
\hline Observations (Days) & 9,496 & 9,487 & 9,487 & 9,487 \\
\hline
\end{tabular}


Table E2: Mass Shooting Fatalities and News Coverage

\begin{tabular}{|c|c|c|c|c|}
\hline \multicolumn{5}{|c|}{ Dependent variable: $\log (1+$ Seconds of News Coverage $)$} \\
\hline Mass Shooting Fatalities & $\begin{array}{c}0.282^{* * *} \\
(0.028)\end{array}$ & $\begin{array}{c}0.284^{* * *} \\
(0.028)\end{array}$ & $\begin{array}{c}0^{0.280^{* * *}} \\
(0.027)\end{array}$ & $\begin{array}{c}0.273^{* * *} \\
(0.026)\end{array}$ \\
\hline \multicolumn{5}{|l|}{ Lags of Fatalities (Days): } \\
\hline L1 & $\begin{array}{l}0.307^{* * *} \\
(0.030)\end{array}$ & $\begin{array}{l}0.308^{* * *} \\
(0.030)\end{array}$ & $\begin{array}{l}0.306^{* * *} \\
(0.030)\end{array}$ & $\begin{array}{l}0.299^{* * * *} \\
(0.029)\end{array}$ \\
\hline L2 & & $\begin{array}{c}0.175^{* * *} \\
(0.029)\end{array}$ & $\begin{array}{l}0.175^{* * *} \\
(0.029)\end{array}$ & $\begin{array}{l}0.169^{* * *} \\
(0.028)\end{array}$ \\
\hline L3 & & $\begin{array}{l}0.167^{* * *} \\
(0.028)\end{array}$ & $\begin{array}{l}0.166^{* * *} \\
(0.028)\end{array}$ & $\begin{array}{l}0.160^{* * *} \\
(0.026)\end{array}$ \\
\hline L4 & & $\begin{array}{l}0.118^{* * *} \\
(0.033)\end{array}$ & $\begin{array}{l}0.119^{* * *} \\
(0.033)\end{array}$ & $\begin{array}{l}0.114^{* * *} \\
(0.031)\end{array}$ \\
\hline L5 & & $\begin{array}{l}0.142^{* * *} \\
(0.032)\end{array}$ & $\begin{array}{l}0.146^{* * *} \\
(0.032)\end{array}$ & $\begin{array}{l}0.141^{* * *} \\
(0.031)\end{array}$ \\
\hline L6 & & $\begin{array}{l}0.119^{* * *} \\
(0.031)\end{array}$ & $\begin{array}{l}0.120^{* * *} \\
(0.031)\end{array}$ & $\begin{array}{l}0.115^{* * *} \\
(0.028)\end{array}$ \\
\hline L7 & & $\begin{array}{l}0.120^{* * *} \\
(0.028)\end{array}$ & $\begin{array}{l}0.117^{* * *} \\
(0.028)\end{array}$ & $\begin{array}{c}0.112^{* * *} \\
(0.028)\end{array}$ \\
\hline L8 & & $\begin{array}{c}0.082^{* * *} \\
(0.028)\end{array}$ & $\begin{array}{l}0.079^{* * *} \\
(0.029)\end{array}$ & $\begin{array}{l}0.073^{* * *} \\
(0.027)\end{array}$ \\
\hline L9 & & $\begin{array}{r}0.053 \\
(0.034)\end{array}$ & $\begin{array}{r}0.053 \\
(0.035)\end{array}$ & $\begin{array}{r}0.047 \\
(0.031)\end{array}$ \\
\hline L10 & & $\begin{array}{c}0.065^{* *} \\
(0.033)\end{array}$ & $\begin{array}{c}0.064^{*} \\
(0.033)\end{array}$ & $\begin{array}{c}0.058^{*} \\
(0.031)\end{array}$ \\
\hline Constant & $\begin{array}{l}1.543^{* * *} \\
(0.025)\end{array}$ & $\begin{array}{l}1.440^{* * *} \\
(0.026)\end{array}$ & $\begin{array}{l}1.120^{* * *} \\
(0.060)\end{array}$ & $\begin{array}{c}0.905^{* * *} \\
(0.150)\end{array}$ \\
\hline \multicolumn{5}{|l|}{ Fixed Effects } \\
\hline Day-of-week & No & No & Yes & Yes \\
\hline Month & No & No & No & Yes \\
\hline Year & No & No & No & Yes \\
\hline Observations (Days) & 9,496 & 9,487 & 9,487 & 9,487 \\
\hline
\end{tabular}




\section{Appendix F: Predicting Mass Shootings}

Table F1: Linear Probability Model for Mass Shooting using Control Variables Dependent variable: indicator for state-year with a mass shooting.

(1)

Lag Bills Introduced

Lag Laws Enacted

Lag Tightening Laws

Lag Loosening Laws

Dem. Legislature

Rep. Legislature

Rep. Governor

Log Population

Elderly (65+) \%

Under $25 \%$

Black \%

Hispanic \%

Unemployment \%

Income per capita

High School \%

Veteran \%

Divorced \%

(0.010)

State FE

Year FE

Observations
(2)

(3) $-0.000$ (0.001)
(4)

(5)

(6)
$-0.002$

(0.006)

$-0.002$

(0.010)

\begin{tabular}{|c|c|c|c|c|c|}
\hline & & & & & $\begin{array}{r}0.009 \\
(0.015)\end{array}$ \\
\hline & 0.006 & 0.004 & 0.005 & 0.005 & 0.006 \\
\hline & $(0.044)$ & $(0.046)$ & $(0.046)$ & $(0.045)$ & $(0.045)$ \\
\hline & -0.030 & -0.029 & -0.028 & -0.028 & -0.029 \\
\hline & $(0.036)$ & $(0.038)$ & $(0.037)$ & $(0.037)$ & $(0.038)$ \\
\hline & -0.012 & -0.011 & -0.011 & -0.011 & -0.011 \\
\hline & $(0.020)$ & $(0.022)$ & $(0.022)$ & $(0.022)$ & $(0.022)$ \\
\hline 0.191 & -0.131 & -0.200 & -0.192 & -0.196 & -0.199 \\
\hline 0.279$)$ & $(0.265)$ & $(0.291)$ & $(0.290)$ & $(0.288)$ & $(0.290)$ \\
\hline 0.001 & -0.001 & 0.004 & 0.004 & 0.004 & 0.004 \\
\hline 0.025$)$ & $(0.024)$ & $(0.024)$ & $(0.024)$ & $(0.024)$ & $(0.024)$ \\
\hline 0.002 & 0.001 & 0.003 & 0.002 & 0.002 & 0.002 \\
\hline 0.020$)$ & (0.019) & $(0.020)$ & $(0.020)$ & $(0.019)$ & $(0.020)$ \\
\hline 0.009 & -0.009 & -0.002 & -0.001 & -0.001 & 0.000 \\
\hline 0.015$)$ & (0.015) & $(0.018)$ & (0.018) & $(0.018)$ & (0.018) \\
\hline 0.001 & -0.003 & -0.002 & -0.003 & -0.003 & -0.003 \\
\hline 0.015$)$ & $(0.015)$ & $(0.016)$ & $(0.016)$ & $(0.016)$ & $(0.016)$ \\
\hline $0.025^{* *}$ & $0.025^{* *}$ & $0.024 * *$ & $0.024 * *$ & $0.024 * *$ & $0.024 * *$ \\
\hline 0.011$)$ & $(0.011)$ & $(0.011)$ & $(0.011)$ & $(0.011)$ & $(0.011)$ \\
\hline 0.013 & 0.012 & 0.011 & 0.012 & 0.012 & 0.011 \\
\hline 0.013$)$ & $(0.013)$ & $(0.014)$ & $(0.014)$ & $(0.014)$ & $(0.014)$ \\
\hline 0.004 & -0.003 & -0.003 & -0.003 & -0.003 & -0.003 \\
\hline 0.006$)$ & $(0.006)$ & $(0.006)$ & $(0.006)$ & $(0.006)$ & $(0.006)$ \\
\hline 0.003 & -0.001 & -0.005 & -0.005 & -0.005 & -0.004 \\
\hline 0.012$)$ & $(0.012)$ & $(0.013)$ & $(0.013)$ & $(0.012)$ & $(0.012)$ \\
\hline 0.004 & -0.003 & -0.001 & -0.001 & -0.001 & -0.001 \\
\hline 0.010$)$ & $(0.010)$ & $(0.011)$ & $(0.011)$ & $(0.011)$ & $(0.011)$ \\
\hline Yes & Yes & Yes & Yes & Yes & Yes \\
\hline Yes & Yes & Yes & Yes & Yes & Yes \\
\hline 1,250 & 1,250 & 1,200 & 1,200 & 1,200 & 1,200 \\
\hline
\end{tabular}


Table F2: Linear Probability Model for Mass Shooting using Policy Variables

Dependent variable: indicator for state-year with a mass shooting.

(1)

\begin{tabular}{|c|c|c|}
\hline Handgun Waiting Period (days) & $\begin{array}{r}0.002 \\
(0.005)\end{array}$ & $\begin{array}{r}0.002 \\
(0.005)\end{array}$ \\
\hline Long-gun Waiting Period (days) & $\begin{array}{r}-0.005 \\
(0.019)\end{array}$ & $\begin{array}{r}-0.005 \\
(0.020)\end{array}$ \\
\hline Age $18+$ for Transaction & $\begin{array}{r}0.031 \\
(0.026)\end{array}$ & $\begin{array}{r}0.026 \\
(0.028)\end{array}$ \\
\hline Age $21+$ for Transaction & $\begin{array}{r}-0.067 \\
(0.057)\end{array}$ & $\begin{array}{r}-0.080 \\
(0.056)\end{array}$ \\
\hline Handgun Permit System & $\begin{array}{r}-0.137 \\
(0.094)\end{array}$ & $\begin{array}{r}-0.136 \\
(0.100)\end{array}$ \\
\hline Background Check, All Handgun Sales & $\begin{array}{r}-0.066 \\
(0.080)\end{array}$ & $\begin{array}{r}-0.066 \\
(0.085)\end{array}$ \\
\hline Background Check, All Firearm Sales & $\begin{array}{r}0.019 \\
(0.116)\end{array}$ & $\begin{array}{r}-0.005 \\
(0.127)\end{array}$ \\
\hline Assault Weapons Ban & $\begin{array}{r}0.042 \\
(0.051)\end{array}$ & $\begin{array}{r}0.050 \\
(0.053)\end{array}$ \\
\hline Shall Issue Concealed Carry & $\begin{array}{r}-0.010 \\
(0.038)\end{array}$ & $\begin{array}{r}-0.006 \\
(0.039)\end{array}$ \\
\hline No Permit Needed Concealed Carry & $\begin{array}{r}0.162 \\
(0.188)\end{array}$ & $\begin{array}{r}0.181 \\
(0.184)\end{array}$ \\
\hline Log Population & $\begin{array}{r}-0.494 \\
(0.325) \\
\end{array}$ & $\begin{array}{r}-0.445 \\
(0.310) \\
\end{array}$ \\
\hline Political Controls & No & Yes \\
\hline Demographic Controls & Yes & Yes \\
\hline State FE & Yes & Yes \\
\hline Year FE & Yes & Yes \\
\hline Observations & 1,250 & 1,250 \\
\hline
\end{tabular}

Note: Handgun Waiting Period is the number of days purchasers must wait before accepting delivery of a handgun. Longgun Waiting Period is similarly defined for long-guns (e.g. rifles and shotguns). Age 18+ Transaction is an indicator for laws that prevent vendors from selling handguns to minors or prevent minors from purchasing handguns. Age 21+ Transaction is defined the same way for persons under 21. Handgun Permit System is an indicator for states that require permits to purchase a handgun. Background Check, All Handgun Sales is an indicator for requiring a background check for all handgun transactions (including private sales). Background Check, All Firearm Sales is an indicator for requiring a background check for all firearm transactions (including private sales). Assault Weapons Ban is an indicator for states that ban some types of assault rifles or pistols. Shall Issue Concealed Carry is an indicator for states that require the permitting authority to grant a license to anyone meeting the minimum statutory qualifications (i.e. do not permit law enforcement discretion in issuing permits). No Permit Needed Concealed Carry is an indicator for states that allow concealed carry without a permit. 
Appendix G: Placebo Mass Shooting Analyses

Table G1: Placebo Analysis for Bill Introductions (Mirrors Table 2)

\begin{tabular}{lrrrrrrr}
\hline & & \multicolumn{7}{c}{ Percentiles of Placebo Test Statistic } \\
\cline { 3 - 8 } & Actual & $\mathbf{1}^{\text {st }}$ & $\mathbf{5}^{\text {th }}$ & $\mathbf{1 0}^{\text {th }}$ & $\mathbf{9 0}^{\text {th }}$ & $\mathbf{9 5}^{\text {th }}$ & $\mathbf{9 9}^{\text {th }}$ \\
\hline Shooting Indicator (model 4) & 2.07 & -3.98 & -2.89 & -2.47 & 0.55 & 0.87 & 1.59 \\
Shooting Fatalities (model 8) & 3.29 & -3.81 & -2.87 & -2.45 & 0.71 & 1.10 & 1.93 \\
\hline
\end{tabular}

Table G2: Placebo Analysis for Enacted Laws (Mirrors Table 5)

\begin{tabular}{lccccccc}
\hline & & \multicolumn{7}{c}{ Percentiles of Placebo Test Statistic } \\
\cline { 3 - 8 } & Actual & 1st & 5th & 10th & 90th & 95th & 99th \\
\hline Tightening Laws (models 2, 4) & & & & & & & \\
$\quad$ Pooled Shooting & -0.49 & -2.19 & -1.43 & -1.07 & 1.83 & 2.25 & 3.10 \\
$\quad$ Dem. Leg. $\times$ Shooting & 0.05 & -2.43 & -1.61 & -1.35 & 1.48 & 1.96 & 2.84 \\
$\quad$ Rep. Leg. $\times$ Shooting & 0.01 & -2.89 & -1.71 & -1.23 & 1.62 & 2.24 & 3.41 \\
$\quad$ Split Leg. $\times$ Shooting & -0.95 & -2.57 & -1.49 & -1.01 & 2.07 & 2.56 & 3.95 \\
Loosening Laws (models 6, 8) & & & & & & & \\
$\quad$ Pooled Shooting & 1.51 & -3.21 & -2.26 & -1.88 & 0.82 & 1.24 & 2.03 \\
$\quad$ Dem. Leg. $\times$ Shooting & -0.63 & -2.64 & -1.85 & -1.41 & 1.23 & 1.60 & 2.97 \\
$\quad$ Rep. Leg. $\times$ Shooting & 3.09 & -3.02 & -2.27 & -1.98 & 0.71 & 1.09 & 1.73 \\
$\quad$ Split Leg. $\times$ Shooting & 0.40 & -2.93 & -2.02 & -1.59 & 1.34 & 1.79 & 2.72 \\
\hline
\end{tabular}

Notes: We randomly assign placebo mass shootings to state-years in which no actual shooting occurred with probability equal to each state's frequency of shootings, and randomly draw a fatality count from the empirical distribution of fatalities. We then re-run the models and calculate the test statistic for the placebo shooting and fatality coefficients. The above percentiles are based on 1,000 replications. The "Pooled" rows in Table $\mathrm{G} 2$ mirror models 2 and 6 of Table 5 (the models without interaction effects). The legislature effects mirror models 4 and 8 for tightening and loosening laws respectively. 


\section{Appendix H: Dropping Individual States}

These analyses exclude each state, one at a time, from our sample. Each graph plots the resulting 50 regression coefficients (from smallest to largest) along with a 95\% confidence interval and estimates using the full sample of all states. The state abbreviations in the figures indicate the state that was dropped from the sample and mark the resulting point estimate. The vertical bars represent $95 \%$ confidence intervals. The solid, horizontal line indicates the point estimate from the complete sample (presented in the text and tables). The dotted, horizontal lines represent the lower and upper bounds of the $95 \%$ confidence interval for the full sample coefficient estimate.

The results show that removing individual states has little effect on the coefficient estimates, supporting the claim that the effect of mass shootings on gun policy is not driven by an individual state or shooting. 
Figure H1 Effect of Mass Shooting on Bill Introductions.

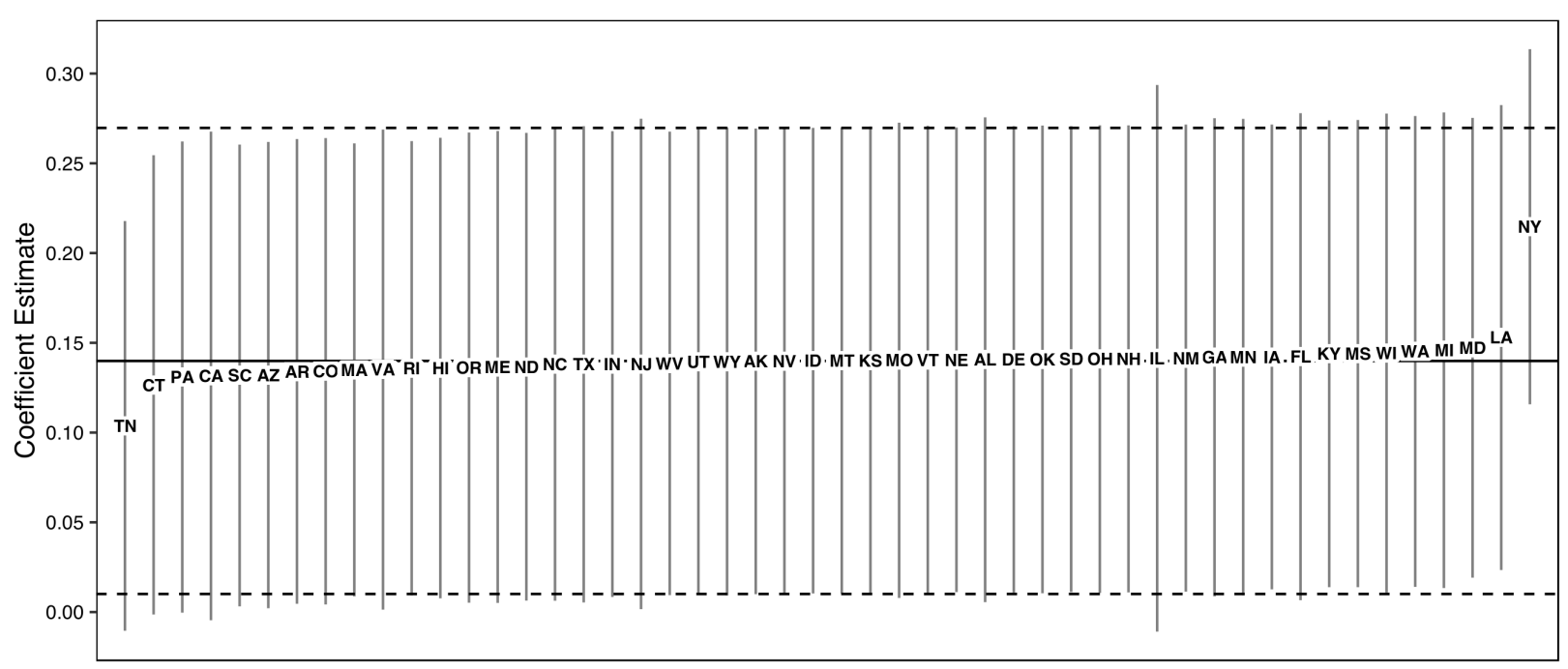

Figure H2 Effect of Mass Shooting on Laws (of Any Type) Enacted.

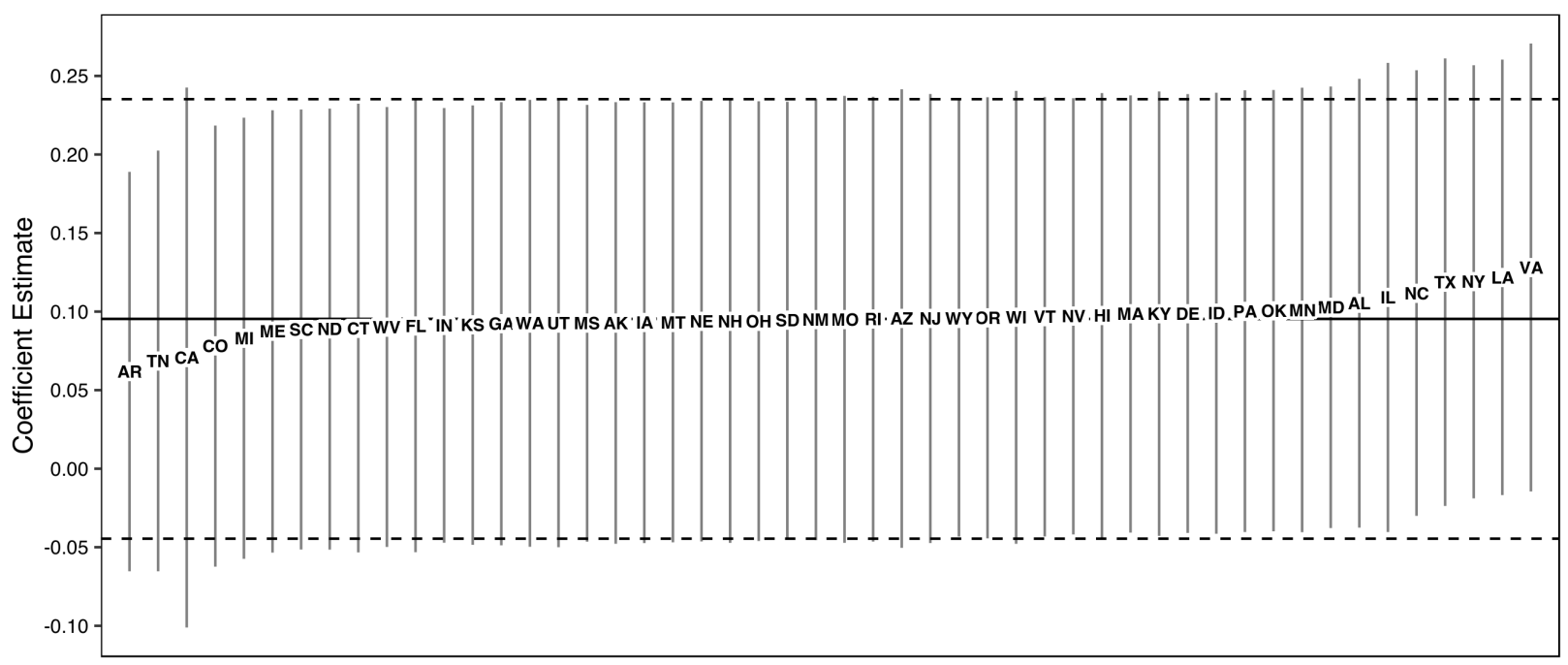


Figure H3 Effect of Republican Legislature Mass Shooting on Loosening Laws Enacted.

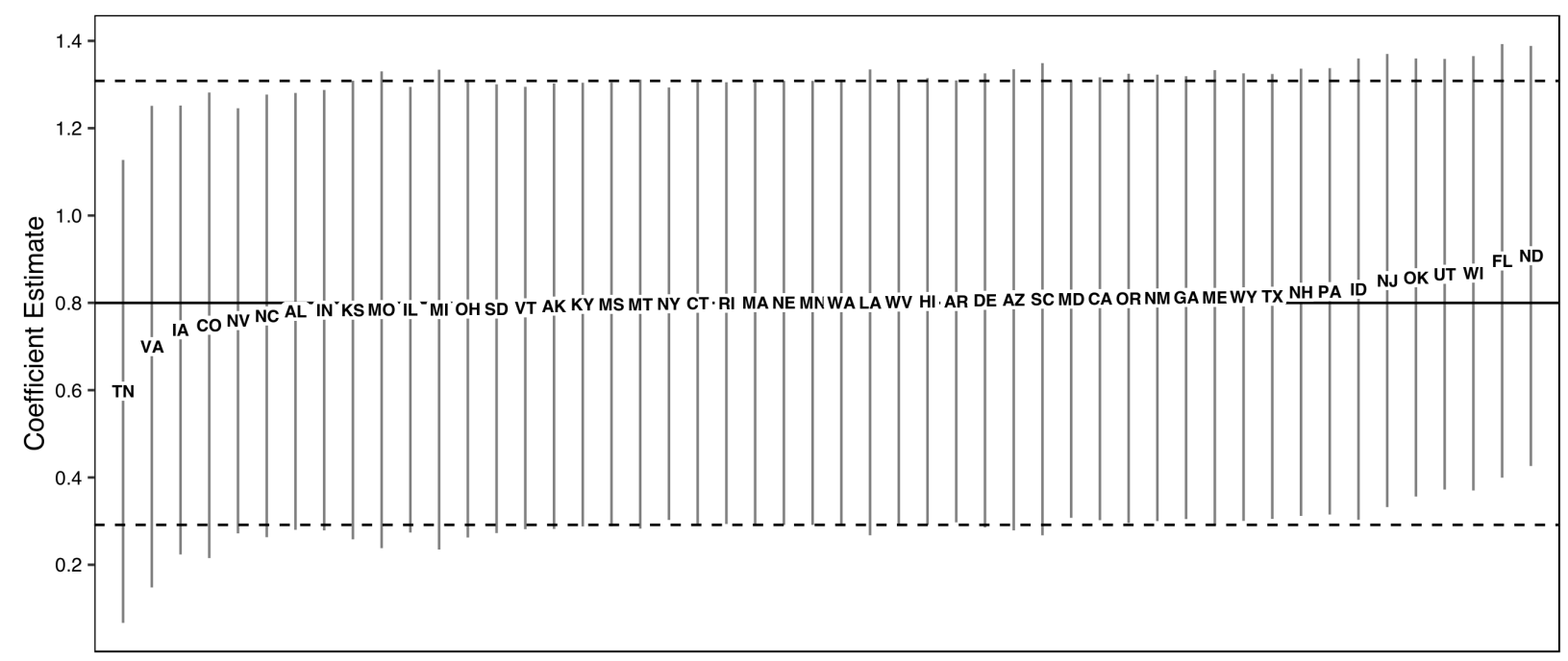

Figure H4 Effect of Democratic Legislature Mass Shooting on Loosening Laws Enacted.

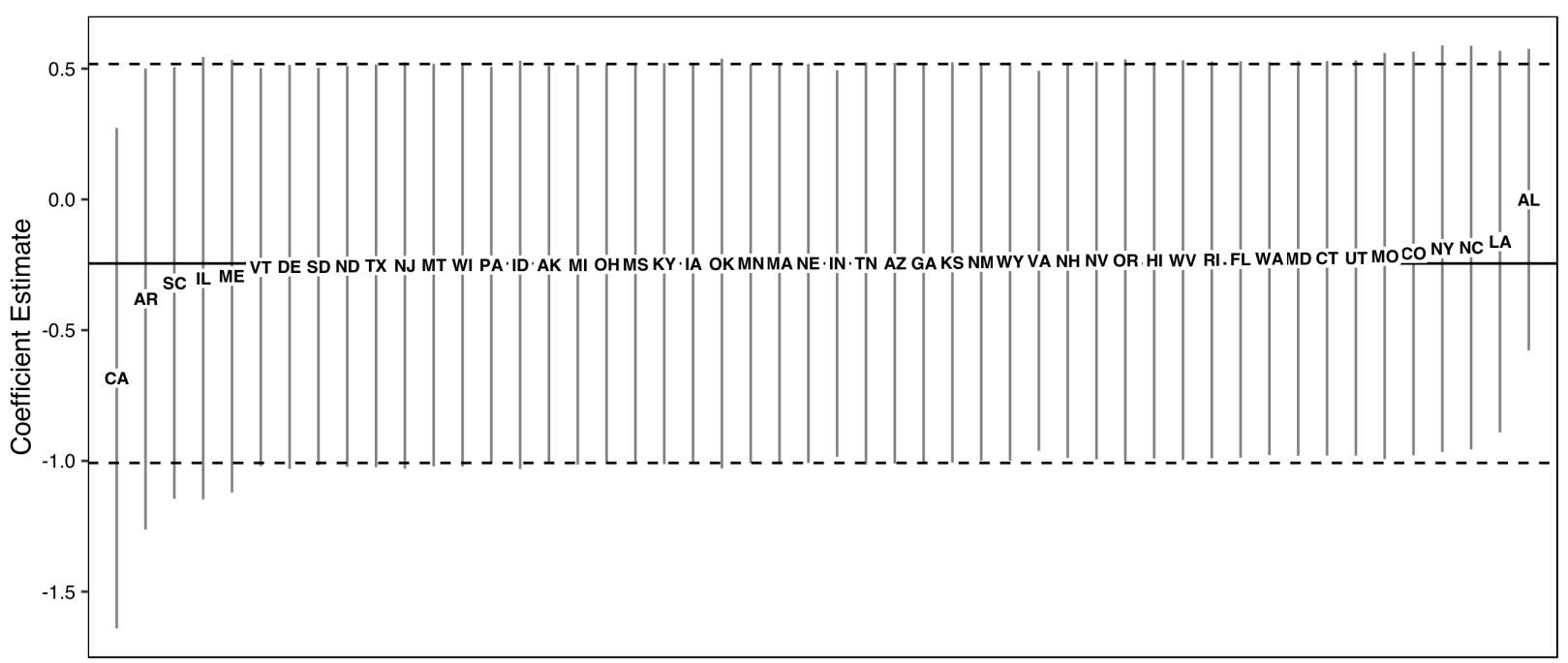


Figure H5 Effect of Republican Legislature Mass Shooting on Tightening Laws Enacted.

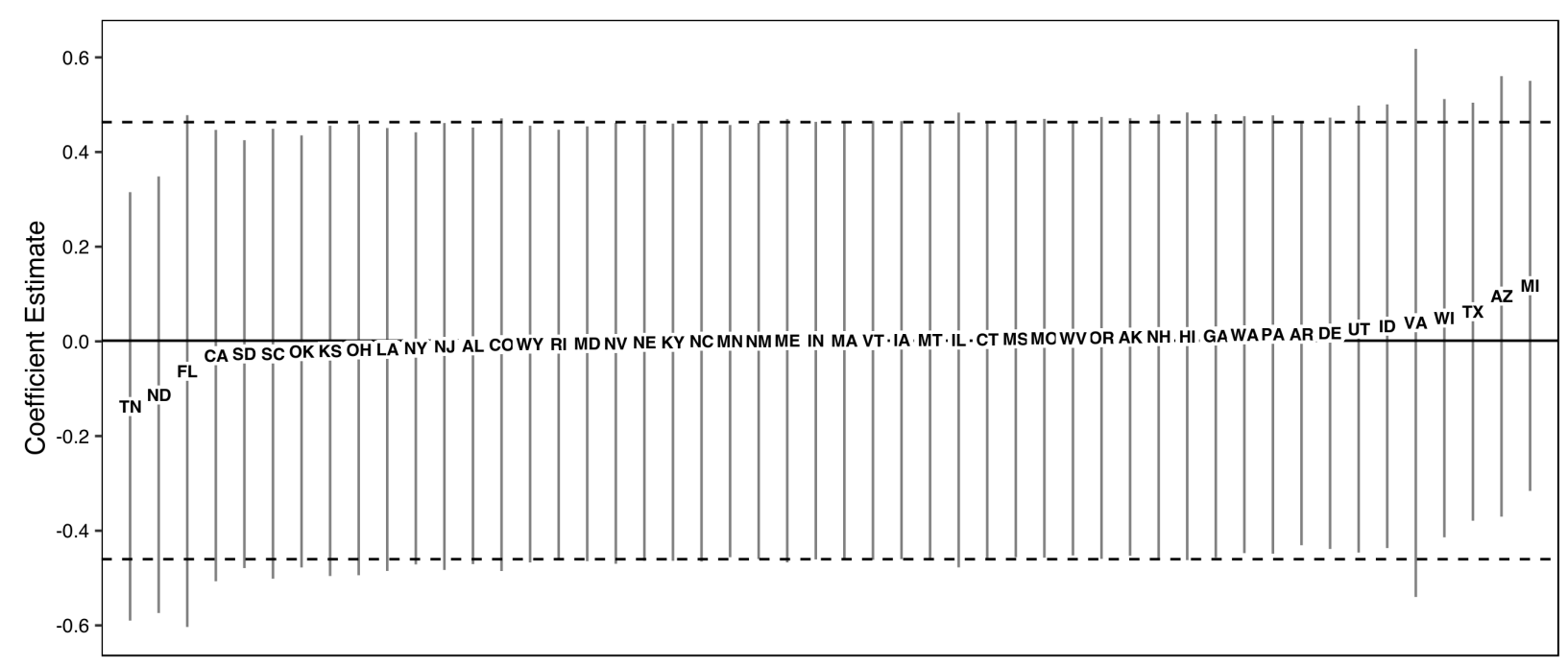

Figure H6 Effect of Democratic Legislature Mass Shooting on Tightening Laws Enacted.

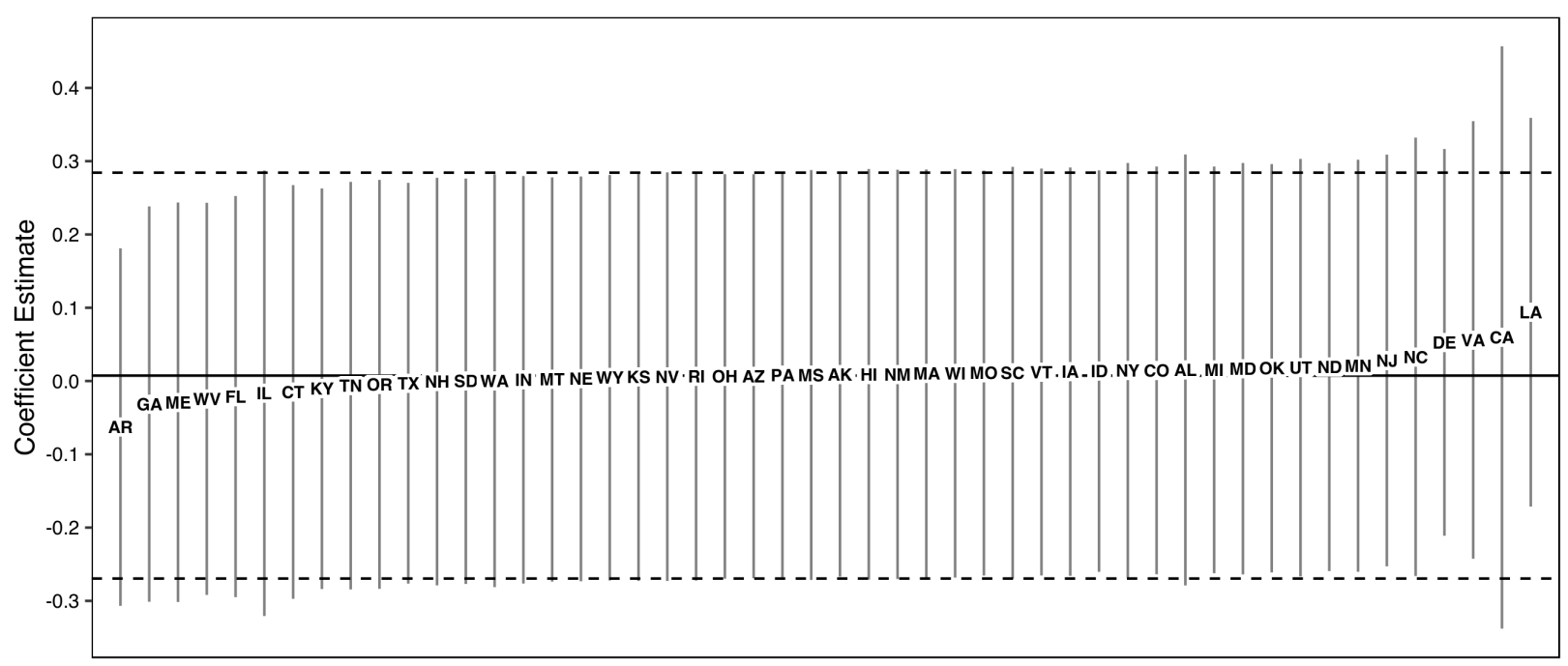




\section{Appendix I: Gun Ownership, Mass Shootings and Enacted Laws}

Table 11: Effects of Mass Shootings, with Gun Ownership Proxy

\begin{tabular}{|c|c|c|c|c|c|c|}
\hline Dependent variable: numb & firearm-relat & $\begin{array}{l}\text { d laws enact } \\
\text { htening Lav }\end{array}$ & (i.e. bills $t$ & ame law & osening Law & \\
\hline & (1) & (2) & (3) & (4) & (5) & (6) \\
\hline Dem. Leg. $\times$ Shooting & 0.016 & 0.006 & & -0.192 & 0.414 & \\
\hline & $(0.141)$ & $(0.452)$ & & $(0.417)$ & $(0.690)$ & \\
\hline Rep. Leg. $\times$ Shooting & 0.003 & -0.008 & & $0.787 * * *$ & $1.439 *$ & \\
\hline & $(0.233)$ & $(0.575)$ & & $(0.265)$ & $(0.807)$ & \\
\hline Split Leg. $\times$ Shooting & -0.240 & -0.250 & & 0.157 & 0.763 & \\
\hline & $(0.259)$ & $(0.581)$ & & $(0.345)$ & $(0.776)$ & \\
\hline Gun Suicide Pct. $\times$ Shooting & & 0.000 & -0.001 & & -0.011 & 0.005 \\
\hline & & $(0.009)$ & $(0.002)$ & & $(0.013)$ & $(0.003)$ \\
\hline Gun Suicide Pct. & 0.039 & 0.039 & 0.039 & $0.107 *$ & $0.110 *$ & $0.113 *$ \\
\hline & $(0.027)$ & $(0.028)$ & $(0.027)$ & $(0.060)$ & $(0.061)$ & (0.059) \\
\hline Democratic Legislature & 0.054 & 0.054 & 0.094 & -0.237 & -0.245 & -0.291 \\
\hline & $(0.171)$ & $(0.171)$ & $(0.150)$ & $(0.227)$ & $(0.222)$ & (0.199) \\
\hline Republican Legislature & 0.131 & 0.131 & 0.167 & $0.412 *$ & $0.402 *$ & $0.517^{* * *}$ \\
\hline & $(0.141)$ & $(0.142)$ & $(0.132)$ & $(0.216)$ & $(0.217)$ & $(0.190)$ \\
\hline Republican Governor & -0.042 & -0.042 & -0.041 & -0.077 & -0.068 & -0.102 \\
\hline & $(0.084)$ & $(0.085)$ & $(0.085)$ & $(0.164)$ & $(0.163)$ & $(0.167)$ \\
\hline Regular Session & $3.225 * * *$ & $3.225^{* * *}$ & $3.220 * * *$ & $17.931^{* * *}$ & $17.934 * * *$ & $16.262 * * *$ \\
\hline & $(0.780)$ & (0.779) & $(0.778)$ & $(0.460)$ & $(0.460)$ & $(0.454)$ \\
\hline First Year of Biennium & 0.037 & 0.037 & 0.032 & $0.443 * * *$ & $0.439 * *$ & $0.403^{* * *}$ \\
\hline & $(0.112)$ & $(0.110)$ & $(0.110)$ & $(0.168)$ & $(0.171)$ & $(0.129)$ \\
\hline Demographic Controls & Yes & Yes & Yes & Yes & Yes & Yes \\
\hline State Fixed Effects & Yes & Yes & Yes & Yes & Yes & Yes \\
\hline Year Fixed Effects & Yes & Yes & Yes & Yes & Yes & Yes \\
\hline Observations & 1,250 & 1,250 & 1,250 & 1,250 & 1,175 & 1,175 \\
\hline
\end{tabular}

Note: Robust standard errors clustered by state in parentheses. Stars following coefficients represent $p$-values less than $.10(*), .05(* *)$ and $.01(* * *)$. Gun Suicide Pct. is the 5-year moving average of the percentage of suicides that are firearmrelated and is used to proxy for gun ownership (Cook and Ludwig 2006). Models 1 and 4 show that the main results do not change when adding this control variable; the other models suggest that the response of Republican legislatures cannot be explained by rates of gun ownership. See note to Table 1 for other variable definitions. 


\section{Appendix J: Mass Shootings as an Instrument for Gun Policy}

In this appendix we use mass shootings as an instrumental variable to study the impact of gun laws on gun deaths. We start with the following model:

$$
\ln \left(D_{s t}\right)=\alpha_{s}+\theta_{t}+\beta \text { Gun } \text { Control }_{s t}+\delta^{\prime} Z_{s t}+\epsilon_{s t}
$$

where $D_{s t}$ is non-mass shooting gun deaths per 100,000 people in state $s$ and year $t, \alpha_{s}$ and $\theta_{t}$ are state

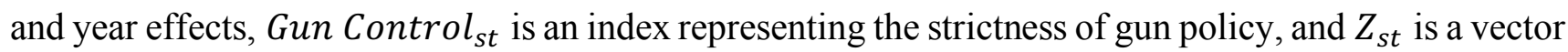
of controls - demographic, political, and economic factors - that potentially affect gun deaths. We use the same variables as Levitt (1996) as controls, but also include dummies for Republican and Democratic trifectas or legislatures, and a dummy for Republican governors.

We do not directly observe Gun Control $_{\text {st }}$; instead, we observe the enactment of new laws that change gun policy. Therefore, we estimate the equation in first differences:

$$
\Delta \ln \left(D_{s t}\right)=\lambda_{t}+\beta \text { New Gun Laws } s_{s t}+\Delta Z_{s t} \delta+\Delta \epsilon_{s t}
$$

where New Gun Laws $=\Delta$ Gun Control st is negative for laws that loosen gun control and positive for laws that increase gun control (according to our coders, see data description). Based on our main results, we instrument for gun laws using the first lags of mass shooting fatalities and the interaction of lagged mass shooting fatalities with Republican control of state government. The former should be positively correlated with new laws and the latter negatively correlated with new laws.

We estimate the model using Fuller's (1977) modified LIML with $\alpha=1$ (Baum, Schaffer, and Stillman 2007). First stage results suggest the instruments are weak despite being jointly significant $(F=5.98)$ with the expected sign (Stock and Yogo 2005). The coefficients on the exogenous instruments in the reduced form equation for firearm deaths are not significant, but also have the expected signs (negative for lagged mass shooting fatalities and positive for the interaction of lagged fatalities with Republican control of government). Our estimate $\hat{\beta}$ is -0.016 with standard error 0.013 . 
A conditional likelihood ratio test (Moreira 2003; Andrews, Moreira, and Stock 2004; Finlay and Magnusson 2009) cannot reject the null hypothesis that $\beta=0(p=0.24)$. We also estimated models that include proxies for gun ownership. Including the percentage of suicides committed with a gun (Cook and Ludwig 2006) does not change our inference. 